\title{
Saturated Heavier Group 14 Compounds as $\sigma$-Electron-Acceptor (Z-Type) Ligands
}

\section{Kameo Hajime, Nakazawa Hiroshi}

\begin{tabular}{|c|l|}
\hline Citation & THE CHEMICAL RECORD. 17(3); 268-286. \\
\hline Issue Date & 2017-03-16 \\
\hline Type & Journal Article \\
\hline Textversion & Author \\
\hline Rights & $\begin{array}{l}\text { This is the peer reviewed version of the following article: Nakazawa H and Kameo } \\
\text { Hajime (2017), Saturated Heavier Group 14 Compounds as math formula } \\
\text {-Electron-Acceptor (Z-Type) Ligands. Chem. Rec.,17:268-286, which has been } \\
\text { published in final form at https://doi.org/10.1002/tcr.201600061. This article may be } \\
\text { used for non-commercial purposes in accordance With Wiley-VCH Terms and } \\
\text { Conditions for self-archiving. } \\
\text { This is the accept manuscript version. Please cite only the published version. } \\
\text { 引用の際には出版社版をご確認ご利用ください。 }\end{array}$ \\
\hline DOI & 10.1002/tcr.201600061 \\
\hline
\end{tabular}

\author{
Self-Archiving by Author(s) \\ Placed on: Osaka City University
}

Kameo Hajime, Nakazawa Hiroshi. (2017). Saturated Heavier Group 14 Compounds as $\sigma$-Electron-Acceptor (Z-Type) Ligands. THE CHEMICAL RECORD. 17, 268-286.

https://doi.org/10.1002/tcr.201600061 
Saturated Heavier Group 14 Compounds as $\sigma$-Electron Acceptor (Z-type) Ligands Hajime Kameo ${ }^{*[b]}$ and Hiroshi Nakazawa*[a]

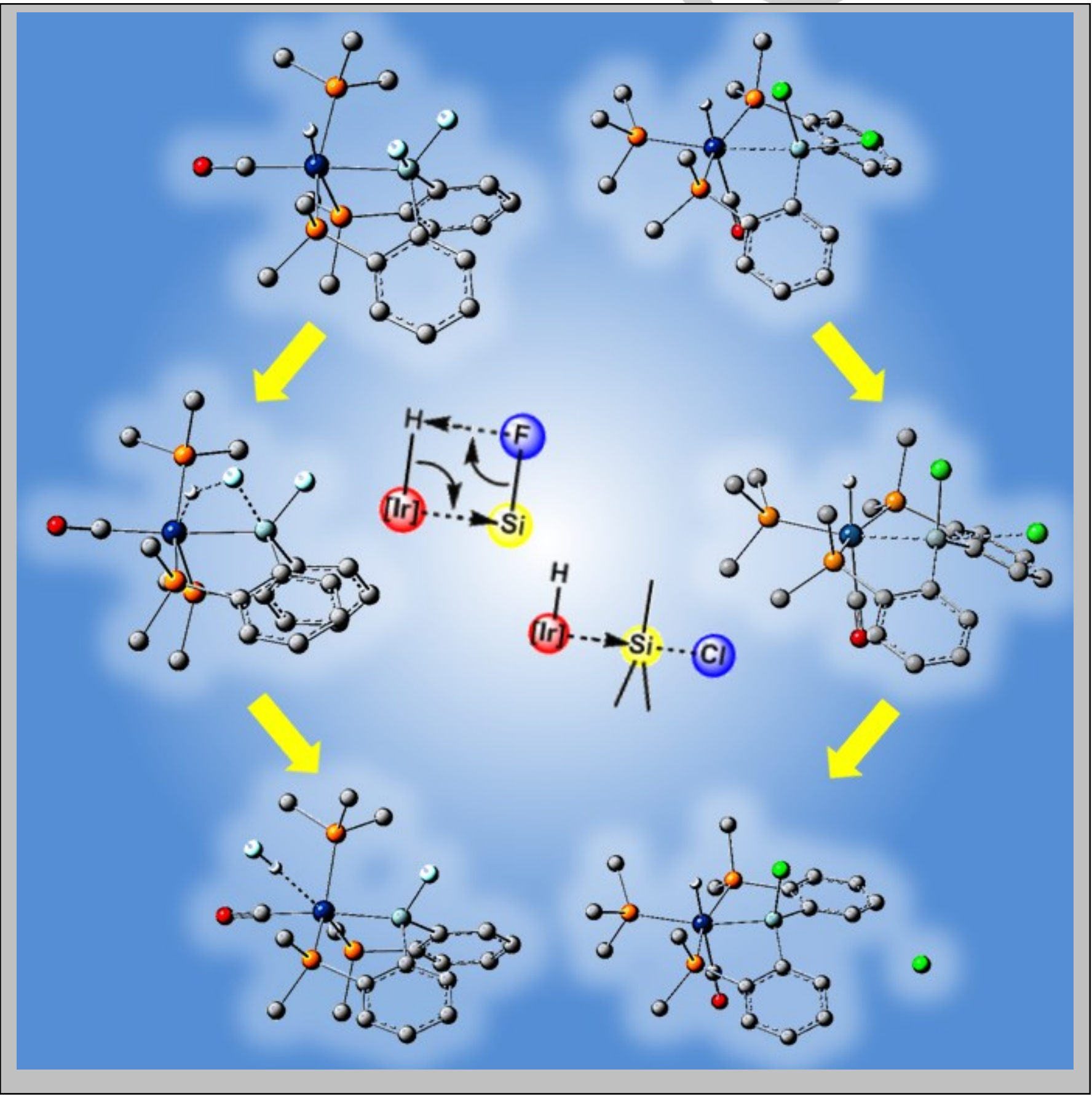


Abstract: This review article describes the chemistry of transition-metal complexes containing heavier Group 14 elements ( $\mathrm{Si}, \mathrm{Ge}$, and $\mathrm{Sn}$ ) as the $\sigma$-electron acceptor (Z-type) ligands and discusses the characteristics of bonds between the transition metal and Z-type ligand. Moreover, we review the iridium-hydride-mediated cleavage of $E-X$ bonds $(E=S i, G e ; X$ $=\mathrm{F}, \mathrm{Cl}$ ), where the key intermediates are pentacoordinate silicon or germanium compounds bearing a dative $M \rightarrow E$ bond.

\section{Introduction}

Silicon, germanium, and tin belong to the Group 14 elements in the periodic table, and hence they are the congeners of carbon. Considering their positions in the periodic table, the compounds of these heavier Group 14 elements are expected to exhibit similar properties as their carbon analogs. However, significant differences are observed between the compounds based on carbon and other Group 14 elements. For example, pentacoordinate carbon compounds are extremely rare ${ }^{[1]}$ whereas heavier Group 14 elements often form penta- and hexacoordinate species with nucleophiles such as Lewis bases. ${ }^{[2]}$ This is strongly related to the two following properties of heavier Group 14 elements (hereafter, $\mathrm{Si}, \mathrm{Ge}$, and $\mathrm{Sn}$ are described as $E$ in this paper): (i) One is the large atomic radii of $\mathrm{E}$; the atomic radius of $\mathrm{Si}$ is 1.5 times larger than that of carbon; germanium and tin have more larger atomic radii (C: $0.76 \AA$, Si: $1.11 \AA$, Ge: $1.20 \AA$, Sn: $1.39 \AA) .{ }^{[3]}$ Therefore, the steric repulsions among the substituents on $E$ significantly decrease in heavier Group 14 compounds. (ii) The other is the electropositive property of E; the Allred-Rochow electronegativity values $(\chi)$ of heavier Group 14 elements $\left(\chi_{\mathrm{Si}}=1.74, \chi_{\mathrm{Ge}}=2.02\right.$, $\left.\chi_{\mathrm{Sn}}=1.72\right)$ are significantly smaller than that of carbon $\left(\chi_{\mathrm{C}}=\right.$ 2.50); thus, E readily electrostatically interacts with nucleophiles. Therefore, tetrahedral heavier Group 14 compounds can accept nucleophile(s) to form trigonal bipyramidal (TBP) or octahedral geometries. These features also contribute to different mechanisms of $\mathrm{S}_{\mathrm{N}} 2$-type reactions occurring at Group 14 element center. In general, when $S_{N}$ 2-type reactions using an organic Lewis base occur at a carbon center, the transition state involves a pentacoordinate species. In contrast, when $\mathrm{S}_{\mathrm{N}} 2$-type reactions using an organic Lewis base occur at a heavier Group 14 element center, the pentacoordinate species often becomes an intermediate, which is isolable in some cases. ${ }^{[4]}$

Along with the progress in organometallic chemistry, $\mathrm{S}_{\mathrm{N}} 2$-type

[a] Prof. H. Nakazawa

Department of Chemistry

Graduate School of Science, Osaka City University

Sugimoto 3-3-138, Sumiyoshi-ku, Osaka 558-8585, Japan

Fax: $(+)+81-6-6605-2522$

E-mail: nakazawa@sci.osaka-cu.ac.jp

[b] Dr. H. Kameo

Department of Chemistry

Graduate School of Science, Osaka Prefecture University

Gakuen-cho 1-1, Naka-ku, Sakai, Osaka 599-8531, Japan

Fax: $(+)+81-72-254-9697$

E-mail: h.kameo@c.s.osakafu-u.ac.jp oxidative addition induced by transition metals has been very important as one of the bond activation processes, leading to diverse molecular transformations (Scheme 1$){ }^{[5]}$ In the $S_{N} 2$-type oxidative addition of Group 14 compounds $\mathrm{EXR}_{3}$, transition metals can be considered as the nucleophiles, and the intermediates and transition states have a dative $\mathrm{M} \rightarrow \mathrm{EXR}_{3}$ interaction resulting from a charge-transfer (CT) interaction between the doubly occupied $\mathrm{d}$ orbital and the antibonding orbital of the E-X bonds. ${ }^{[6]}$ In other words, saturated Group 14 moieties $\mathrm{EXR}_{3}$ act as $\sigma$ electron acceptor for Lewis basic transition metals. ${ }^{[7]}$ According to Green's classifications, the moieties bound to a transition metal are classified as Z-type ligands, which are sharply distinguished from the conventional Land X-type ligands (Chart 1). ${ }^{[7 a]}$ The geometric and electronic structures of compounds bearing a Z-type saturated Group 14 ligand are very informative for the better understanding and further applications of $S_{N}$ 2-type reactions. The use of heavier Group 14 compounds would facilitate the synthesis of models for the intermediates or transition states. Moreover, these compounds with $\mathrm{d}(\mathrm{M}) \rightarrow \sigma^{*}(\mathrm{E}-\mathrm{X})$ interaction may become important synthetic intermediates, because the electronacceptor ligands will be activated by the electron donation from the transition metals to the antibonding orbitals. Specifically, the activation of silicon-fluoride and silicon-chloride bonds is generally difficult using transition-metal complexes because of their large bond dissociation energies $\left(D_{\mathrm{Si}-\mathrm{F}}=540 \mathrm{~kJ} / \mathrm{mol}, D_{\mathrm{Si}-\mathrm{Cl}}=\right.$ $456 \mathrm{~kJ} / \mathrm{mol}){ }^{[8]}$ However, their low antibonding orbital energies potentially induce strong $\mathrm{d}(\mathrm{M}) \rightarrow \sigma^{*}(\mathrm{Si}-\mathrm{F})$ and $\mathrm{d}(\mathrm{M}) \rightarrow \sigma^{*}(\mathrm{Si}-\mathrm{Cl})$ interactions, leading to the subsequent bond activation and transformation. The transition-metal-mediated transformations of $\mathrm{Si}-\mathrm{F}$ and $\mathrm{Si}-\mathrm{Cl}$ bonds, particularly if catalytic cleavage becomes possible, may provide a novel strategy in silicon synthetic chemistry.

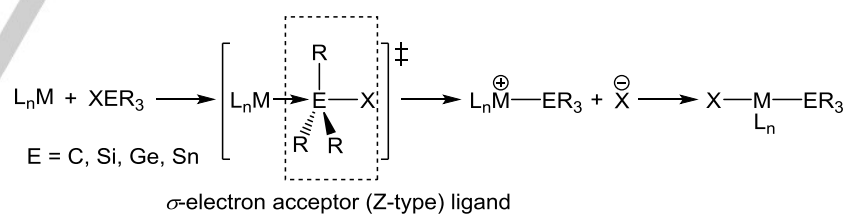

Scheme 1. $S_{N}$ 2-type oxidative addition.
i) Z-type Ligand
ii) L-type Ligand
iii) X-type Ligand
$\mathrm{M}: \longrightarrow \mathrm{Z}$
$M \longleftarrow: L$
two electrons are provided by $L$

$$
\mathrm{M}: \mathrm{X}
$$
one electron is provided by $X$ and by $M$

Chart 1. Three coordination styles of ligands.

This review article describes the chemistry of transition-metal complexes containing heavier Group 14 elements as Z-type ligands, and the characteristics of bonds between the transition metal and Z-type ligand based on E. Before describing this main topic, let us briefly introduce transition-metal complexes bearing a borane compound serving as the Z-type ligand, because 
boranes have been extensively studied as Z-type ligands for complexation with transition metals. ${ }^{[9]}$

Hajime Kameo received his PhD in 2009 at Tokyo Institute of Technology under the guidance of Professor Hiroharu Suzuki. After a postdoctoral stint with Professor Karsten Meyer at Erlangen-Nuremberg University (2009-2010), he became a special appointment Lecturer at Osaka City University (2010-2013). In 2013, he joined Osaka Prefecture University as an Assistant Professor. His main research interest is the chemistry of transition-metal clusters and $\sigma$ electron-acceptor ligands.

Hiroshi Nakazawa received his B. Sc. degree in 1975 from Science University of Tokyo, M. Sc. and Ph. D degrees in 1978 and 1981, respectively, from Hiroshima University under the supervision of Professor Hayami Yoneda. From 1981 to 1982 he worked with Professor Akio Yamamoto at Tokyo Institute of Technology and from 1982 to 1984 with Professor J. A. Gladysz at University of Utah as a postdoctoral research fellow. He became a research associate at Hiroshima University in 1984, and promoted to an associate professor in 1990. From 1994 to 1996 he was appointed an associate professor of Institute for Molecular Science. Since 2002 , he has been a full professor of Osaka City University.

\section{Chemistry of transition-metal complexes bearing borane as the Z-type ligand}

One of the reasons for the development of $\mathrm{M} \rightarrow \mathrm{BR}_{3}$ complexes is the unique nature of Z-type ligands in affording novel electronic structures. The bonds between boranes and transition metals provide an ambiguous oxidation state to the metal center (Chart 2, left), because a $M \rightarrow B$ bond can have two extremes: (i) the lone pair electrons used in $\mathrm{M} \rightarrow \mathrm{B}$ belong to $\mathrm{M}$, i.e., the oxidation state of $M$ does not change after the $M \rightarrow B$ bond formation, (ii) the lone pair electrons belong to $B$ after the $M \rightarrow B$ bond formation, showing that the oxidation state of $M$ increases by two after $M \rightarrow B$ bond formation. Bourissou's analysis using the ${ }^{197} \mathrm{Au}$ Mössbauer spectroscopy of diphosphine-borane gold chloride complexes $\mathbf{1 a}$ and $\mathbf{1 b}$ (Chart 3, left) nicely demonstrated the main contribution of description (i) in the $A u \rightarrow B$ bond: a significant amount of $A u \rightarrow B$ interaction was observed (Au-B distances $/ \sum$ (covalent radius) $=2.309(8)(1 \mathrm{a})$ and $2.335(5)(\mathbf{1 b}) / 2.20, \Sigma(C B C)$ (sum of angles of $C-B-C)=$ 341 (1a) and $344(\mathbf{1 b})) .{ }^{[10]}$ Peters also reported that the $\mathrm{Fe} \rightarrow \mathrm{B}$ bond in cationic triphosphine-borane iron complex 2 ( $\mathrm{Fe}-\mathrm{B}$ distance $/ \sum$ (covalent radius) $=2.217 \AA / 2.16 \AA, \Sigma(C B C)=347^{\circ}$ ) had a stronger contribution of description (i) than (ii) (Chart 3 , right). ${ }^{[11]}$ We have been interested in the effects of borane ligands on the geometry and reactivity of transition-metal complexes. ${ }^{[12]}$ We synthesized octahedral iridium complex 3 bearing a triphosphine-borane ligand. The Ir-B distance in $\mathbf{3}$ $(2.326(11) \AA)$ is comparable to the sum of their covalent radii $(2.23 \AA)$, and the pyramidalization around the boron atom $\left(\Sigma(C B C)=330.9^{\circ}\right)$ is remarkable (Scheme 2). ${ }^{[12 b]}$ These geometric features undoubtedly indicate that 3 has one of the strongest $M \rightarrow B$ interaction. Complex 3 induced the facile loss of $\mathrm{CO}$ ligand in the reactions with $\mathrm{PR}_{3}(\mathrm{R}=\mathrm{OMe}, \mathrm{Me})$. No example was found for iridium $(\mathrm{I})$ complexes releasing $\mathrm{CO}$ ligand without changing the oxidation state, and hence the reactivity of $\mathbf{3}$ was strongly influenced by the borane ligand. Crabtree commented on our reactions and pointed out that the octahedral geometry around the iridium center and the easy loss of $\mathrm{CO}$ ligand indicate $d^{6}$ rather than $d^{8}$ electron configuration (description (ii) in Chart 1), i.e., the coordination of borane changed the oxidation state (Chart 3). ${ }^{[13]}$ This comment was, at least in part, supported by our natural localized molecular orbital (NLMO) analysis of $\mathbf{3}$ (Table 1). The contribution of $B$ orbitals to the Ir-B bond was only slightly smaller than that of $\mathrm{H}$ orbital to the $\mathrm{Ir}-\mathrm{H}$ bond. Furthermore, the hybridization of Ir orbital in the Ir-B bond was similar to that in the $\mathrm{Ir}-\mathrm{H}$ bond, indicating the resemblance of bonding situation between the Ir-B and Ir-H bonds (Chart 4). In general, the formation of a $\mathrm{M}-\mathrm{H}$ bond through protonation increases the formal oxidation state of $M$ by two units, i.e., $M\left(d^{n}\right)$ to $M\left(d^{n-2}\right)$. The empty orbitals (1s orbital for the proton and $2 p$ orbital for borane) similarly affect transition metals by accepting the lone pair electrons on the metal fragment, suggesting a larger contribution of description (ii) than (i) to the Ir-B bond in $\mathbf{3}$ (Chart 4).

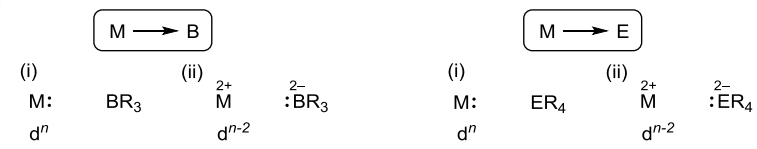

Chart 2. Two models contributing to $\mathrm{M} \rightarrow \mathrm{BR}_{3}$ and $\mathrm{M} \rightarrow \mathrm{ER} R_{4}$ bonds.
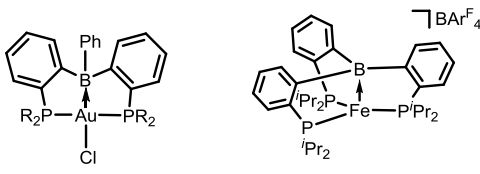

$\mathrm{R}=\operatorname{Ph}(\mathbf{1} \mathbf{a}), \operatorname{Pr}(\mathbf{1} \mathbf{b})$

2: $\mathrm{Ar} F=3,5-\mathrm{C}_{6} \mathrm{H}_{3}\left(\mathrm{CF}_{3}\right)_{2}$

Chart 3. Bourissou's gold(I) complexes 1 and Peters's iron(I) complex 2.

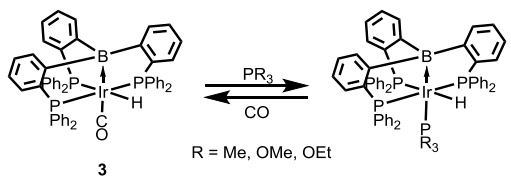

Scheme 2. Reversible CO/P exchange reaction induced by borane ligand. 
Table 1. NLMO data for the $\mathrm{Ir}-\mathrm{B}$ and $\mathrm{Ir}-\mathrm{H}$ bonds in $\mathbf{3}$

\begin{tabular}{|c|c|c|c|c|c|c|c|}
\hline \multirow[t]{2}{*}{ Bonds } & \multicolumn{2}{|c|}{ Orbital contribution } & \multicolumn{3}{|c|}{ Ir hybrid } & \multicolumn{2}{|c|}{$\mathrm{B}$ or $\mathrm{H}$ hybrid } \\
\hline & $\operatorname{Ir}(\%)$ & $\mathrm{B}$ or $\mathrm{H}(\%)$ & $\mathrm{s}(\%)$ & $p(\%)$ & $d(\%)$ & $\mathrm{s}(\%)$ & $\mathrm{p}(\%)$ \\
\hline Ir-B & 58.5 & $30.6(\mathrm{~B})$ & 3.6 & 24.1 & 72.3 & 20.0 & 80.0 \\
\hline $\mathrm{Ir}-\mathrm{H}$ & 54.2 & $38.3(\mathrm{H})$ & 7.7 & 19.5 & 72.8 & 100 & 0 \\
\hline
\end{tabular}

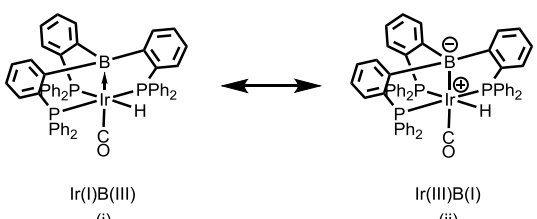

Chart 4. Possible resonance structures of octahedral iridium borane complex 3

\section{Chemistry of transition-metal complexes} bearing $\mathrm{ER}_{4}(\mathrm{E}=\mathrm{Si}, \mathrm{Ge}, \mathrm{Sn})$ as the Z-type ligand

As Z-type saturated Group 14 ligands E are also expected to provide novel electronic structures, interpretation of $M \rightarrow E$ interactions becomes a subject of some debate. Therefore, contribution of at least two extremes to $\mathrm{M} \rightarrow \mathrm{ER}_{4}$ bonding should be considered similar to borane ligand chemistry (Chart 2): (i) the original oxidation state of the metal center $\left(d^{n}\right)$ and the coordinated neutral Group 14 ligand $\mathrm{ER}_{4}$, and (ii) the divalent oxidation state of the metal center $\left(\mathrm{d}^{\mathrm{n}-2}\right)$ and dianionic $\mathrm{ER}_{4}{ }^{2-}$. Consideration of contribution of two extreme configurations is one of the subjects in this review article. In general, $\mathrm{S}_{\mathrm{N}} 2$-type reactions necessarily accompany with a change from a dative interaction to a covalent bond, and hence the electronic structures including a Z-type saturated Group 14 ligand are clearly located between those of a reactant and of a product in $\mathrm{S}_{\mathrm{N}} 2$-type reactions and should be considered as precise models of transition states and intermediates.

\subsection{Metallosilatranes consisting of three chelating frameworks of $-\mathrm{XCH}_{2} \mathrm{PMe}_{2}$ groups $\left(\mathrm{X}=\mathrm{O}, \mathrm{CH}_{2}\right)$}

In 1994, Grobe et al. reported the pioneering work on metallosilatrane. ${ }^{[14]}$ They analyzed the structure of $\mathrm{MeSi}\left(\mathrm{OCH}_{2} \mathrm{PMe}_{2}\right)_{3} \mathrm{Ni}(\mathrm{CO})$ (4, Chart 5), which was synthesized by the reaction of a tripodal ligand with $\mathrm{Ni}(\mathrm{CO})_{4}$ in a moderate yield. ${ }^{[14 a]}$ The Ni-Si distance $(3.941(2) \AA)$ in 4 is longer than the sum of covalent radii $(2.35 \AA)$, but slightly shorter than the sum of the van der Waals radii $(4.10 \AA){ }^{[15]}$ implying the presence of $\mathrm{Ni} \rightarrow \mathrm{Si}$ interaction. To evaluate the strengths of $\mathrm{M} \rightarrow \mathrm{E}$ interactions, " $r$ factor" was defined as $r=\mathrm{d}_{\mathrm{ME}} /\left(R_{c o v}(\mathrm{M})+R_{\text {cov }}\right.$ (E)) where $\mathrm{d}_{\mathrm{ME}}$ and $R_{\text {cov }}$ are the M-E distance and covalent radius, respectively. The $r$ factor of the $\mathrm{Ni} \rightarrow \mathrm{Si}$ interaction in 4 was calculated to be 1.68. The sum of the $\mathrm{O}-\mathrm{Si}-\mathrm{O}$ angles involving three methylene groups was calculated to be $349.1^{\circ}$, implying a slight change from tetrahedral to TBP geometry. These geometric features indicated weak but significant $\mathrm{Ni} \rightarrow \mathrm{Si}$ interaction.

Furthermore, they analyzed the structures of the $\mathrm{PPh}_{3}$ analog $\mathrm{MeSi}\left(\mathrm{OCH}_{2} \mathrm{PMe}_{2}\right)_{3} \mathrm{Ni}\left(\mathrm{PPh}_{3}\right)$ (5) of 4 and $\mathrm{FSi}\left(\mathrm{CH}_{2} \mathrm{CH}_{2} \mathrm{PMe}_{2}\right)_{3} \mathrm{Ni}\left(\mathrm{PPh}_{3}\right)$ (6) with a similar structure as 4 except for the atoms adjacent to the Si center. ${ }^{[14 b]}$ The Ni-Si distance in 5 (3.95 $\AA, r=1.68)$ is comparable to that in $\mathbf{4}$, whereas the $\mathrm{Ni}-\mathrm{Si}$ distance in 6 (3.92 $\AA, r=1.67)$ is slightly shorter than that in $\mathbf{4}$ despite the fact that $\mathbf{6}$ has a $\mathrm{PPh}_{3}$ group, larger than $\mathrm{CO}$ group. Further, the sum of the three $\mathrm{C}-\mathrm{Si}-\mathrm{C}$ angles in $6\left(349.1^{\circ}\right)$ is larger than that of the three O-Si-O angles in $5\left(332.7^{\circ}\right)$. These geometrical data imply that the stronger Lewis acidity of SiF moiety than SiMe moiety induces a stronger $\mathrm{Ni} \rightarrow \mathrm{Si}$ interaction.

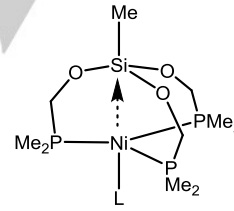

4: $L=C O$ 5: $L=P P h_{3}$

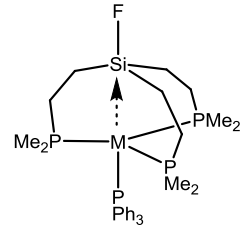

6: $\mathrm{M}=\mathrm{Ni}$

7: $M=P d$
Chart 5. Grobe's metallosilatranes 4-8

Grobe et al. reported another example; $\mathrm{FSi}\left(\mathrm{CH}_{2} \mathrm{CH}_{2} \mathrm{PMe}_{2}\right)_{3} \mathrm{Pd}$ was synthesized by the reaction of $\mathrm{Pd}\left(\mathrm{PPh}_{3}\right)_{4}$ with $\mathrm{FSi}\left(\mathrm{CH}_{2} \mathrm{CH}_{2} \mathrm{PMe}_{2}\right)_{3} \cdot{ }^{[16]}$ Although the structural analysis of $\mathrm{FSi}\left(\mathrm{CH}_{2} \mathrm{CH}_{2} \mathrm{PMe}_{2}\right)_{3} \mathrm{Pd}$ failed, they confirmed the structure of the $\mathrm{PPh}_{3}$ adduct $\mathrm{FSi}\left(\mathrm{CH}_{2} \mathrm{CH}_{2} \mathrm{PMe}_{2}\right)_{3} \mathrm{Pd}\left(\mathrm{PPh}_{3}\right)(7)$, which can be considered as the nickel analog of 6 . The $\mathrm{Pd}-\mathrm{Si}$ distance $(3.875 \AA)$ in 7 is slightly shorter than the $\mathrm{Ni}-\mathrm{Si}$ distance in $\mathbf{6}$, despite a larger covalent radius of palladium $(1.39 \AA)^{[3]}$ than nickel $(1.24 \AA){ }^{[3]}$ The $\boldsymbol{r}$ factor was calculated to be 1.55 , and a Wiberg bond index (WBI) of 0.0245 supported the significant interaction between $\mathrm{Si}$ and $\mathrm{Pd}$. Several attempts to synthesize the platinum analog $\mathrm{FSi}\left(\mathrm{CH}_{2} \mathrm{CH}_{2} \mathrm{PMe}_{2}\right)_{3} \mathrm{Pt}\left(\mathrm{PPh}_{3}\right)$ (8) of 4 and 7 were unsuccessful, but they predicted with density functional theory (DFT) calculations that the $\mathrm{Pt}-\mathrm{Si}$ distance in $\mathbf{8}$ is shorter than the M-Si distances in $\mathbf{6}$ and $\mathbf{7}$.

\subsection{Saturated heavier Group 14 ligands supported by 0 -} $\left(\mathrm{R}_{2} \mathrm{P}\right) \mathrm{C}_{6} \mathrm{H}_{4}$ groups $(\mathrm{R}=i \mathrm{Pr}, \mathrm{Ph})$ 
In 2009, Bourissou and co-workers reported several important compounds bearing saturated heavier Group 14 ligands. $^{[17]}$ They used rigid ortho-phenylene spacers to place the $\mathrm{M}$ and $\mathrm{E}$ at appropriate positions, and gold silane and stannane complexes $\left\{\left(\mathrm{Pr}_{2} \mathrm{P}\right) \mathrm{C}_{6} \mathrm{H}_{4}\right\}_{2}(\mathrm{Ph})(\mathrm{X}) \mathrm{E}\{\mathrm{AuCl}\}($ 9: $\mathrm{E}=\mathrm{Si}, \mathrm{X}=\mathrm{F} ; \mathbf{1 0}$ : $\mathrm{E}$ $=\mathrm{Sn}, \mathrm{X}=\mathrm{F} ; 11 \mathrm{E}=\mathrm{Sn}, \mathrm{X}=\mathrm{Cl}$ ) were synthesized by the reactions of $\mathrm{AuCl} \cdot \mathrm{SMe}_{2}$ with diphosphine-silane and -stannane ligands (Scheme 3). The Au-Si distance (3.090(2) $\AA$ ) in 9 is longer than the sum of the covalent radii of gold and silicon $(2.47 \AA)$ but significantly shorter than the sum of their van der Waals radii $(4.20 \AA)$, where the $\boldsymbol{r}$ factor was calculated to be 1.25. This short Au-Si distance is in marked contrast to the M-Si distances observed in Grobe's metallosilatranes ( $r=1.5$ 1.6). The Au-Sn distance in 10 (2.891(1) $\AA$ ) is shorter than the $\mathrm{Au}-\mathrm{Si}$ distance in $\mathbf{9}$, despite a larger covalent radius of Sn (1.39 $\AA)$ than Si $(1.11 \AA),{ }^{[3]}$ and slightly larger than their sum of covalent radii (2.75 $\AA, r=1.05)$. Moreover, the sums of the three $\mathrm{C}-\mathrm{E}-\mathrm{C}$ angles were calculated to be $353.1^{\circ}$ (9) and $355.9^{\circ}(10)$, and a significant change from tetrahedral to TBP geometry was observed. These geometric data imply the presence of significant interactions between Au and Group 14 elements. This conclusion was supported by the spectroscopic and theoretical analyses. The coordination of organic Lewis bases induces a high magnetic field shift in ${ }^{29} \mathrm{Si} \mathrm{NMR} \mathrm{spectra.}$ The coordination of gold caused a shift in the ${ }^{29} \mathrm{Si}$ NMR signal from $\delta-5.2 \mathrm{ppm}$ (free ligand) to $-21.4 \mathrm{ppm}(\mathbf{9})$ by $\Delta=16.2 \mathrm{ppm}$. Similarly, the signals in the ${ }^{119} \mathrm{Sn}$ NMR spectra shifted to a much higher magnetic field for $10(-147 \mathrm{ppm})$ than for tetracoordinate $\mathrm{Ar}_{3} \mathrm{SnF}$ derivatives ( $-65 \mathrm{ppm}$ to $-85 \mathrm{ppm}$ ) and were relatively close to those reported for related amine adducts $(-195 \mathrm{ppm}$ to $-200 \mathrm{ppm})$. Further, the atoms in molecules (AIM) calculations indicated the presence of bond critical points (BCPs) between $\mathrm{Au}$ and $\mathrm{E}$; the electron densities $\rho(\gamma)$ at the BCP were $2.13 \times 10^{-2} \mathrm{e} \mathrm{bohr}^{-3}(9), 3.50 \times 10^{-2} \mathrm{e}$ bohr $^{-3}$ (10), and $3.56 \times 10^{-2} \mathrm{e} \mathrm{bohr}^{-3}$ (11). The second perturbation energies between $\mathrm{Au}$ and $\mathrm{E}$ atoms were calculated to be $7.6 \mathrm{kcal} / \mathrm{mol}(9), 22.8 \mathrm{kcal} / \mathrm{mol}(10)$, and $26.6 \mathrm{kcal} / \mathrm{mol}$ (11). All the geometric, spectroscopic, and theoretical data clearly show the presence of strong dative $A u \rightarrow E$ interactions. Notably, these geometric and electronic features are similar to those predicted computationally for the transition-state structures associated with the $\mathrm{S}_{\mathrm{N}} 2$-type oxidative addition of $\mathrm{C}-\mathrm{X}$ bonds $\left(\mathrm{X}=\right.$ halogen) to transition metals. ${ }^{[6]}$ Another important finding was that the stannane ligand withdrew the electron density from the Au center than the silane ligand.

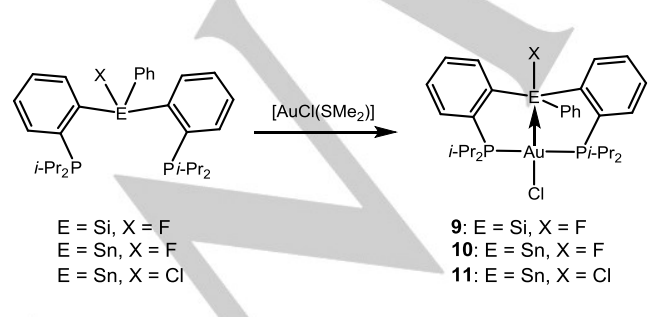

Scheme 3. Synthesis of Gold Silane and Stannane Complexes 9-11.
The analysis of $\mathbf{9}$ in solution using NMR spectroscopy showed the presence of two isomers in a 60:40 ratio (Scheme 4) ${ }^{[18]}$ The major isomer was 9-trans, and the minor isomer was 9-cis bearing the fluorine atom cis to gold. The $2 \mathrm{D}{ }^{31} \mathrm{P}\left\{{ }^{1} \mathrm{H}\right\}$ EXSY NMR experiment indicated dynamic exchange between these two isomers. The geometric features around the Si center are very different between 9-trans and 9-cis. As mentioned above, the $\mathrm{Si}$ center in 9-trans adopts a TBP geometry owing to a significant $A u \rightarrow S i$ interaction. In contrast, the $\mathrm{Si}$ center in an optimized structure of 9-cis adopted a tetrahedral geometry $\left(\Sigma(C E C)=341.33^{\circ}\right)$ rather than a TBP geometry, indicating the absence of a strong $\mathrm{Au} \rightarrow \mathrm{Si}$ interaction: The $\mathrm{Au}-\mathrm{Si}$ distance $(3.452 \AA)$ in 9-cis was much longer than that in 9-trans and the $\boldsymbol{r}$ factor was calculated to be 1.40 for $\mathbf{9 - c i s}$.

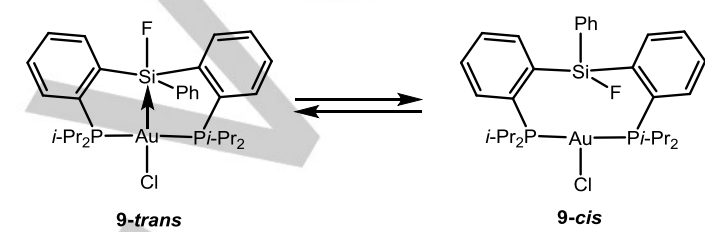

Scheme 4. Dynamic equilibrium between 9-trans and 9-cis

They also analyzed the structure of $\left[\left\{\left(i \mathrm{Pr}_{2} \mathrm{P}\right) \mathrm{C}_{6} \mathrm{H}_{4}\right\}_{2} \mathrm{Si}\left(\mathrm{R}^{1}\right)\left(\mathrm{R}^{2}\right)\right] \mathrm{AuCl}\left(12: \mathrm{R}^{1}=\mathrm{R}^{2}=\mathrm{F} ; 13: \mathrm{R}^{1}=\mathrm{F}, \mathrm{R}^{2}=\right.$ Me; 14: $\left.R^{1}=R^{2}=M e\right)$ to understand the substituent effects on the silicon center (Chart 6 ). The NMR analysis of 13 , unlike $\mathbf{9}$, indicated the presence of only one isomer 13-trans, i.e., 13-cis was absent. The short Au-Si distances in 12 (3.108(1) $\AA, r=$ 1.26) and $13(3.089(3) \AA, r=1.25)$ and the distorted trigonalbipyramidal geometry around the Si center $(\Sigma(\mathrm{CSiC})=352.6$ (12) and 354.2 (13)) were similar to those of 9-trans. In contrast, the geometrical feature of 14 was similar to that of the optimized structure of 9-cis; a relatively longer $\mathrm{Au}-\mathrm{Si}$ distance (3.345(1) $\AA, r=1.35)$ and tetrahedral geometry around the $\mathrm{Si}$ center indicates the absence of strong dative $\mathrm{Au} \rightarrow \mathrm{Si}$ interactions. Further, this conclusion was supported by the fact that the theoretical calculations on $\mathbf{1 4}$ indicated no sign of significant $\mathrm{Au}-\mathrm{Si}$ interaction. These results indicate that $\mathrm{Au} \rightarrow \sigma^{*}(\mathrm{Si}-\mathrm{C})$ interaction is not effective. Another important finding is that an increase in the number of fluorine substituent on $\mathrm{Si}$ does not necessarily induce a stronger dative $\mathrm{Au} \rightarrow \mathrm{Si}$ interaction. It is known that the number of fluorine atoms in a fluorosilane strongly influences its Lewis acidity. For example, Kawashima reported that intramolecular $\mathrm{N} \rightarrow \mathrm{Si}$ interactions were strengthened with the increase in the number of fluorine atoms on silicon. ${ }^{[19]}$ The general knowledge on the interactions of fluorosilanes with Lewis bases is inconsistent with the results obtained that the $\mathrm{Au} \rightarrow \mathrm{Si}$ interactions were not strengthened with the increase in the fluorine substituents on the $\mathrm{Si}$ atom. Presumably, the CT interaction between the occupied d orbital of $\mathrm{Au}$ and the antibonding orbital of the $\mathrm{Si}-\mathrm{F}$ bond dominates the electrostatic effect. 


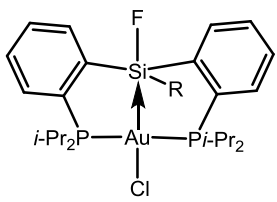

12: $R=F$ 13: $R=M e$

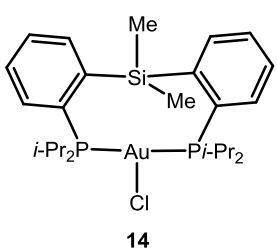

Chart 6. Gold complexes with a dative Au-Si interaction (12 and 13) or without a significant $\mathrm{Au}-\mathrm{Si}$ interaction (14)

Bourissou et al. reported the synthesis of a gold complex [ $\{0-$ $\left.\left.\left(i \mathrm{Pr}_{2} \mathrm{P}\right) \mathrm{C}_{6} \mathrm{H}_{4}\right\}_{3}(\mathrm{~F}) \mathrm{SiAu}\right]^{+}[\mathrm{Cl}]^{-}(\mathbf{1 5 a})$ with a very original trigonal pyramidal geometry. ${ }^{[20,21]}$ The reaction of $\mathrm{AuCl} \cdot \mathrm{SMe}_{2}$ with a tripodal triphosphine-silane ligand afforded cationic gold complex 15a through the elimination of the $\mathrm{Cl}$ ligand (Scheme 5 ) in contrast to the reaction with diphosphine-silane resulting in neutral gold chloride 9 (see Scheme 3). A long Au-Cl distance $(6.911 \AA)$ indicates the absence of a significant interaction between them. Notably, $15 \mathrm{a}$, despite a cationic species, has a very short Au-Si distance (2.970(2) $\AA, r=1.20)$, shorter than those in diphosphine-fluorosilane system such as 9-trans. The natural bond orbital (NBO) and AIM analyses $(\mathrm{Au} \rightarrow \mathrm{Si}$ CT interaction: $15.0 \mathrm{kcal} / \mathrm{mol}$; electron density at the bond critical point (BCP): $2.62 \times 10^{-2} \mathrm{e} \mathrm{bohr}^{-3}$ ) also support the presence of a strong $\mathrm{Au}-\mathrm{Si}$ interaction, comparable to diphosphine system 9-trans. The NMR analysis of 15a indicates the presence of another isomer $\mathbf{1 5 b}$, in which the third phosphine remained pendant, and the fluorine atom was cis to gold. The optimized structure $15 \mathrm{~b}$, similar to 14 , has a long $\mathrm{Au}-\mathrm{Si}$ distance $(3.42 \AA$, $r=1.39)$ due to ineffective $\mathrm{Au} \rightarrow \sigma^{*}(\mathrm{Si}-\mathrm{C})$ interaction. The $2 \mathrm{D}$ ${ }^{31} \mathrm{P}\left\{{ }^{1} \mathrm{H}\right\}$ EXSY NMR experiments did not support a direct exchange between $15 \mathrm{a}$ and $15 \mathrm{~b}$, but the possibility of this exchange was strongly supported by the fact that the coordinated and pendant phosphine donors underwent exchange within the NMR scale. Therefore, the coordination of the third phosphine arm occurred reversibly, and induced a dative $\mathrm{Au} \rightarrow \mathrm{Si}$ interaction and the elimination of $\mathrm{Cl}$ atom, thus affording an unusual trigonal pyramidal geometry.

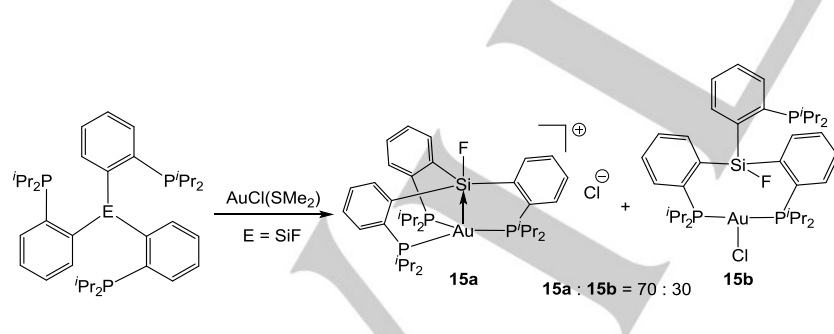

Scheme 5. Synthesis of cationic gold silane complex $15 \mathrm{a}$ with a trigonal pyramidal geometry.

We were interested in the origin of the novel bonding situation, ${ }^{[22]}$ namely, $\mathrm{M} \rightarrow \mathrm{ER}_{4}$ interaction, and investigated the key factor responsible for the strength of $M \rightarrow E$ interaction. Several properties of Group 14 elements such as electronegativity, size, and geometry, would influence the $\sigma$ - electron acceptor ability of heavier Group 14 compounds. Further, this property may vary by soft-hard interaction. Therefore, we became strongly aware of the importance of a systematic study on heavier Group 14 ligands. If the electronegativity of $E$ is the most important factor, then the $\mathrm{M} \rightarrow \mathrm{E}$ interaction becomes stronger in Si (1.74) and Sn (1.72) systems than $\mathrm{Ge}(2.02)$ system. In contrast, if the accessibility of Lewis bases to $E$ atom is the main factor, it is expected that the $\mathrm{M}-\mathrm{E}$ interaction increases in the order $\mathrm{Si}(1.11 \AA)<\mathrm{Ge}(1.20$ $\AA)<\operatorname{Sn}(1.39 \AA)$.

Group 11 metal complexes $\left[\left\{\mathrm{O}-\left(\mathrm{Ph}_{2} \mathrm{P}\right) \mathrm{C}_{6} \mathrm{H}_{4}\right\}_{3}(\mathrm{~F}) \mathrm{Si}\right] \mathrm{MCl}(\mathrm{M}=$ $\mathrm{Cu}$ (16), Ag (17), Au (18)), [\{o-( $\left.\left.\left.\mathrm{Ph}_{2} \mathrm{P}\right) \mathrm{C}_{6} \mathrm{H}_{4}\right\}_{3}(\mathrm{~F}) \mathrm{Ge}\right] \mathrm{MCl}(\mathrm{M}=\mathrm{Cu}$ (19), $\mathrm{Ag}(20), \mathrm{Au}(21))$, and [ $\left.\left[\mathrm{O}-\left(\mathrm{Ph}_{2} \mathrm{P}\right) \mathrm{C}_{6} \mathrm{H}_{4}\right\}_{3}(\mathrm{~F}) \mathrm{Sn}\right] \mathrm{MCl}(\mathrm{M}=\mathrm{Cu}$ (22), $\mathrm{Ag}(23), \mathrm{Au}(24))$ were synthesized by the reactions of triphosphine-silane, -germane, and -stannane ligands [ 0 $\left.\left.\left(\mathrm{Ph}_{2} \mathrm{P}\right) \mathrm{C}_{6} \mathrm{H}_{4}\right\}_{3}(\mathrm{~F}) \mathrm{E}\right](\mathrm{E}=\mathrm{Si}, \mathrm{Ge}, \mathrm{Sn})^{[23]}$ with the corresponding metal chloride (Scheme 6). The M-E distances and $\boldsymbol{r}$ factors are summarized in Table 2, and the Wiberg bond indexes (WBIs) of M-E distances are shown in Table 3. The $r$ factors ranged from 1.43 to 1.08 , and the saturated Group 14 moieties well responded to the Lewis basicity of transition metals, despite the cage structure consisting of three phosphine donors. The $\boldsymbol{r}$ factors in the copper complexes decreased in the order $1.43(16)>1.34(19)>1.17(22)$, which is consistent with the increase in the WBIs between $\mathrm{Cu}$ and $\mathrm{E}$ atoms from 0.054 (16) to 0.077 (19) and $0.145(22)$. The same tendency was observed in silver and gold systems; $\mathrm{Ag}$ ( $\boldsymbol{r}$ factor): $1.36(17)>1.28(20)>$ 1.13 (23); $\mathrm{Au}$ ( $\boldsymbol{r}$ factor): 1.30 (18) > $1.23(\mathbf{2 1})>1.08(\mathbf{2 4}) ; \mathrm{Ag}$ (WBI): 0.056 (17) < 0.081 (20) < 0.160 (23); Au (WBI): 0.114 $(\mathbf{1 8})<0.157(21)<0.243(24)$. These data indicate that the acceptor ability of $\mathrm{E}$ increased in the order $\mathrm{Si}<\mathrm{Ge}<\mathrm{Sn}$. The CT stabilization energy was analyzed by the second-order perturbation with the NBOs (Table 4). Similar to the WBIs, the $M \rightarrow \sigma^{*}(E-F)$ CT interaction gradually increased by going down Group 14 in the periodic table, indicating that $M \rightarrow \sigma^{\star}(E-F)$ CT interaction is the main factor for the strengths of $M-E$ interactions. Because $\mathrm{M} \rightarrow \sigma^{\star}(\mathrm{E}-\mathrm{F})$ interactions depend on the energy levels of $\sigma^{*}(\mathrm{E}-\mathrm{F})$ orbitals, we calculated the energy level of $\sigma^{*}(\mathrm{E}-\mathrm{F})$ orbitals in the frozen $\left\{(\mathrm{O}-\mathrm{H}) \mathrm{C}_{6} \mathrm{H}_{4}\right\}_{3} \mathrm{E}(\mathrm{F})$ fragment $(\mathrm{E}=$ $\mathrm{Si}, \mathrm{Ge}, \mathrm{Sn})$, where the $\mathrm{PPh}_{2}$ group in 18, 21, and 24 was replaced with hydrogens, and the $\mathrm{AuCl}$ moieties were removed. The $\sigma^{*}(\mathrm{E}-\mathrm{F})$ orbitals were involved in the LUMOs of $\{(0-$ $\left.\mathrm{H}) \mathrm{C}_{6} \mathrm{H}_{4}\right\}_{3} \mathrm{E}(\mathrm{F})$ (Figure 1), and their energy levels decreased in the order $-0.84 \mathrm{eV}(\mathrm{E}=\mathrm{Si})>-1.0 \mathrm{eV}(\mathrm{E}=\mathrm{Ge})>-1.7 \mathrm{eV}(\mathrm{E}=$ $\mathrm{Sn})$, indicating that the $\sigma^{*}(\mathrm{E}-\mathrm{F}) \mathrm{MO}$ level is undoubtedly an important factor for inducing $\mathrm{M} \rightarrow \sigma^{*}(\mathrm{E}-\mathrm{F})$ interactions. 


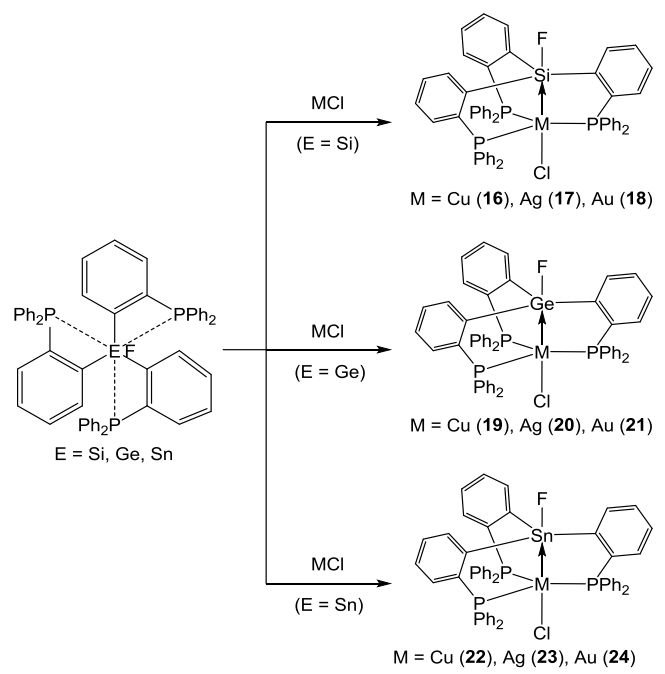

Scheme 6. Synthesis of Group 11 Metal Silane, Germane, and Stannane Complexes 16-24.

Table 2. M-E distance and $r$ factor in 16-24

\begin{tabular}{|c|c|c|c|}
\hline & \multicolumn{3}{|c|}{ M-E distance $[\AA]] / \boldsymbol{r}$ factor } \\
\hline & $\mathrm{M}=\mathrm{Cu}$ & $\mathrm{M}=\mathrm{Ag}$ & $M=A u$ \\
\hline$E=S i$ & $\begin{array}{l}3.4771(17) / 1.43 \\
(16)\end{array}$ & $\begin{array}{l}3.4852(16) / 1.36 \\
(\mathbf{1 7})\end{array}$ & $\begin{array}{l}3.223(2) / 1.30 \\
(\mathbf{1 8 )}\end{array}$ \\
\hline$E=G e$ & $\begin{array}{l}3.3718(9) / 1.34 \\
(19)\end{array}$ & $\begin{array}{l}3.3799(8) / 1.28 \\
(\mathbf{2 0})\end{array}$ & $\begin{array}{l}3.1479(5) / 1.23 \\
(\mathbf{2 1})\end{array}$ \\
\hline$E=S n$ & $\begin{array}{l}3.1791(5) / 1.17 \\
(\mathbf{2 2})\end{array}$ & $\begin{array}{l}3.2082(6) / 1.13 \\
(23)\end{array}$ & $\begin{array}{l}2.9686(3) / 1.08 \\
(\mathbf{2 4})\end{array}$ \\
\hline
\end{tabular}

Table 3. Wiberg Bond Indexes in 16-24

\begin{tabular}{cccc}
\hline & \multicolumn{3}{c}{ Wiberg Bond Index } \\
\hline $\mathrm{M}=\mathrm{Cu}$ & $\mathrm{M}=\mathrm{Ag}$ & $\mathrm{M}=\mathrm{Au}$ \\
\hline $\mathrm{E}=\mathrm{Si}$ & $0.054(\mathbf{1 6})$ & $0.056(\mathbf{1 7})$ & $0.114(\mathbf{1 8})$ \\
$\mathrm{E}=\mathrm{Ge}$ & $0.077(\mathbf{1 9})$ & $0.081(\mathbf{2 0})$ & $0.157(\mathbf{2 1})$ \\
$\mathrm{E}=\mathrm{Sn}$ & $0.145(\mathbf{2 2})$ & $0.160(\mathbf{2 3})$ & $0.243(\mathbf{2 4})$ \\
\hline
\end{tabular}

Table 4. NBO Stabilizing Energies Associated with $M \rightarrow \sigma^{\star}(E-F)$ Interaction $(\mathrm{kcal} / \mathrm{mol})$ in 16-24

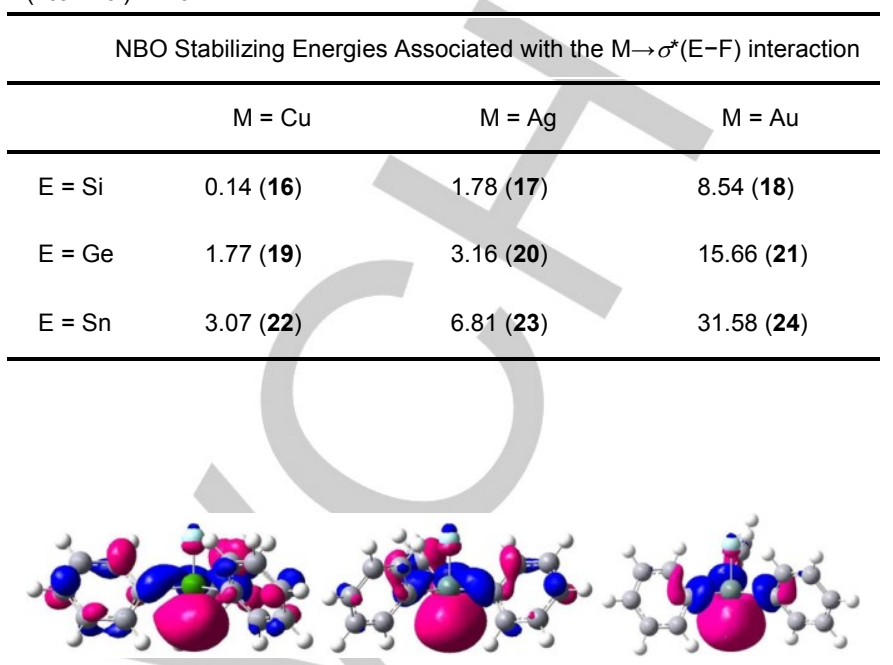

Figure 1. The lowest unoccupied molecular orbitals (LUMOs) of $\{(0-$ $\left.\mathrm{H}) \mathrm{C}_{6} \mathrm{H}_{4}\right\}_{3} \mathrm{E}(\mathrm{F})$ (the $\mathrm{PPh}_{2}$ groups in $18(\mathrm{E}=\mathrm{Si}), 21(\mathrm{E}=\mathrm{Ge})$, and $24(\mathrm{E}=\mathrm{Sn})$ were replaced with hydrogens, and their $\mathrm{AuCl}$ moieties were removed.). Left: $\left\{(o-H) \mathrm{C}_{6} \mathrm{H}_{4}\right\}_{3} \mathrm{Si}(\mathrm{F})(-0.84 \mathrm{eV})$, center: $\left\{(\mathrm{o}-\mathrm{H}) \mathrm{C}_{6} \mathrm{H}_{4}\right\}_{3} \mathrm{Ge}(\mathrm{F})(-1.0 \mathrm{eV})$, right: $\{(\mathrm{o}-$ $\left.\mathrm{H}) \mathrm{C}_{6} \mathrm{H}_{4}\right\}_{3} \mathrm{Sn}(\mathrm{F})(-1.7 \mathrm{eV})$.

Notably, the decreasing order of $\sigma^{*}(\mathrm{E}-\mathrm{F})$ energy level is inconsistent with the order predicted from their electronegativity. How did we understand the order of $\sigma^{*}(\mathrm{E}-\mathrm{F})$ energy level? The $\mathrm{C}-\mathrm{E}-\mathrm{F}$ angle in $\left\{(\mathrm{O}-\mathrm{H}) \mathrm{C}_{6} \mathrm{H}_{4}\right\}_{3} \mathrm{E}(\mathrm{F})$ provided a clue to rationalize the order. The $\mathrm{C}-\mathrm{E}-\mathrm{F}$ angle decreased in the order $96.7^{\circ}(\mathrm{E}=$ $\mathrm{Si})>94.0^{\circ}(\mathrm{E}=\mathrm{Ge})>91.2^{\circ}(\mathrm{E}=\mathrm{Sn})$. The order is parallel to the decreasing order of $\sigma^{\star}(\mathrm{E}-\mathrm{F}) \mathrm{MO}$ level. Theoretical calculations showed that the MO level of $\left\{(\mathrm{O}-\mathrm{H}) \mathrm{C}_{6} \mathrm{H}_{4}\right\}_{3} \mathrm{Sn}(\mathrm{F})$ strongly depended on the geometric environment around the tin atom (Figure 2); the LUMO level of $\left\{(\mathrm{o}-\mathrm{H}) \mathrm{C}_{6} \mathrm{H}_{4}\right\}_{3} \mathrm{Sn}(\mathrm{F})$ decreased with the decreased in $\mathrm{C}-\mathrm{Sn}-\mathrm{F}$ angles in the order $-0.79 \mathrm{eV}\left(106.2^{\circ}\right)>-0.82 \mathrm{eV}\left(101.2^{\circ}\right)>-1.2 \mathrm{eV}\left(96.2^{\circ}\right)>-1.7$ $\mathrm{eV}\left(91.2^{\circ}\right)$. Thus, the structural change around $E$ from tetrahedral to TBP geometry lowered the $\sigma^{\star}(\mathrm{E}-\mathrm{F}) \mathrm{MO}$ level. Generally, when going down a group in the periodic table, the isovalent hybridization becomes less effective and the atomic radius increases. ${ }^{[24]}$ These features energetically facilitate the distortion from a tetrahedral to TBP geometry. This is an important factor for the energetically low $\sigma^{*}(\mathrm{E}-\mathrm{F}) \mathrm{MO}$, leading to a strong $\sigma$-electron acceptor ability. 
Table 5. NLMO data for the Au-E bonds in gold complexes 18, 21, and 24

\begin{tabular}{|c|c|c|c|c|c|c|c|c|}
\hline \multirow[t]{2}{*}{ Compounds } & \multicolumn{2}{|c|}{ Orbital contribution } & \multicolumn{3}{|c|}{ Au hybrid } & \multicolumn{3}{|c|}{ E hybrid } \\
\hline & $\mathrm{Au}(\%)$ & $E(\%)$ & $\mathrm{s}(\%)$ & $\mathrm{p}(\%)$ & $d(\%)$ & $\mathrm{s}(\%)$ & $p(\%)$ & $d(\%)$ \\
\hline $18(\mathrm{E}=\mathrm{Si})$ & 96.1 & 1.9 & 0.6 & 1.6 & 97.8 & 7.5 & 90.5 & 2.0 \\
\hline $21(E=G e)$ & 95.3 & 2.6 & 0.8 & 1.7 & 97.5 & 10.8 & 88.8 & 0.4 \\
\hline $24(E=S n)$ & 94.4 & 3.5 & 1.3 & 2.3 & 96.4 & 21.7 & 78.3 & 0 \\
\hline
\end{tabular}

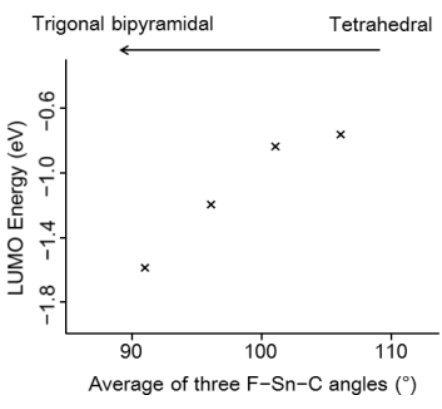

Figure 2. LUMO levels of $\left\{(\mathrm{o}-\mathrm{H}) \mathrm{C}_{6} \mathrm{H}_{4}\right\}_{3} \mathrm{Sn}(\mathrm{F})$ fragments vs the average $\mathrm{C}-\mathrm{Sn}-\mathrm{F}$ angle. The LUMO level decreases with the decrease in the average angle from $106.2^{\circ}$ to $91.2^{\circ}$.

We performed the NLMO analysis of the Au-E interactions in gold complexes 18, 21, and 24 (Table 5). Stronger Au-E bonds have a larger contribution of the $E$ orbital (18: 1.9\%, 21: $2.6 \%$, 24: $3.5 \%)$ and the stronger $s$ character of the $E$ hybrid orbital (18: $7.5 \%, 21: 10.8 \%, 24: 21.7 \%$ ). The results support that heavier Group 14 elements form stronger and more covalent characteristic bonds. On the other hand, even stannane complex 24 includes only small contribution of Sn orbitals to the $\mathrm{Au} \rightarrow \mathrm{Sn}$ bond (Au: $94.4 \%, \mathrm{Sn}: 3.5 \%$ ) and character of doublyoccupied d orbital of the Au center in 18, 21, and 24 is dominant ( $d$ character of the Au orbital: 96.4-97.8\%). These bonding features indicate that the contribution to the $\mathrm{Au}-\mathrm{E}$ bonding in $\mathbf{1 8}, \mathbf{2 1}$, and $\mathbf{2 4}$ is entirely attributed to description (i) in Chart 1.

\subsection{Metallosilatranes and metallostannatranes consisting of buttressing methimazolyl bridges}

Another important scaffold with buttressing methimazolyl bridges was developed by Wagler et al. ${ }^{[25-28]}$ As expected, the presence of an electronegative nitrogen atom adjacent to the Group 14 element becomes more accessible to hypervalent structures. In 2008, they reported paddlewheel-type palladastannatrane complex 25 , which was obtained by the treatment of the sodium salt of methimazole with $\mathrm{PdCl}_{2}(\mathrm{~L})_{2}(\mathrm{~L}=$ $\mathrm{PPh}_{3}, \mathrm{CH}_{3} \mathrm{CN}$ ) followed by the addition of $\mathrm{SnCl}_{4}$ (Scheme 7). ${ }^{[25]}$ The $\mathrm{Pd}-\mathrm{Sn}$ distance $(2.605(1) \AA)$ in 25 is even shorter than not only their sum of covalent radii $(r=0.94)$ but also the distance (2.678(2) $\AA$ ) between the two planes defined by four $\mathrm{N}$ bonded with Sn and four S, respectively. These geometric features strongly indicate the presence of a bonding interaction between the $\mathrm{Pd}$ and $\mathrm{Sn}$ atoms. Further, the AIM analysis of $\mathbf{2 5}$ indicates the presence of a BCP, supporting the above-mentioned bonding interaction. They considered the contributions of some resonance structures including $\mathrm{Pd}^{\prime \prime} \rightarrow \mathrm{Sn}^{\mathrm{IV}}$ (i) and $\mathrm{Sn}^{\mathrm{II}} \rightarrow \mathrm{Pd}^{\mathrm{IV}}$ (ii) interactions (Scheme 8 ). The atomic charge on $\mathrm{Sn}$ is positive (natural charge $(\mathrm{NC}):+2.31$, Mulliken charge: +1.07 ), and that on $\mathrm{Pd}$ is negative (NC: -0.72 , Mulliken charge: -0.89 ). Further, the NBO analysis did not show any bonding and antibonding contribution of the $\mathrm{Pd}-\mathrm{Sn}$ bond, suggesting the predominant ionic character between $\mathrm{Pd}$ and $\mathrm{Sn}$ atoms. These results support the large contribution of dative $\mathrm{Pd}^{\prime \prime} \rightarrow \mathrm{Sn}^{\text {IV }}$ bonding situation (i). A strong covalent character (short distances) of the $\mathrm{Sn}-\mathrm{N}$ bond (2.160(2)-2.168(2) $\AA$ ) is consistent with this conclusion. Notably, the $\mathrm{d}^{8}$ electron configuration was supported rather than the $d^{6}$ electron configuration despite the octahedral geometry around the palladium center.

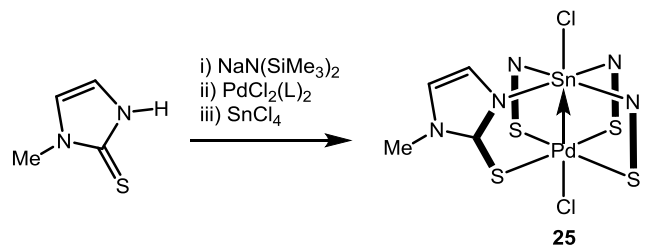

Scheme 7. Synthesis of palladastannatrane $\mathbf{2 5}$

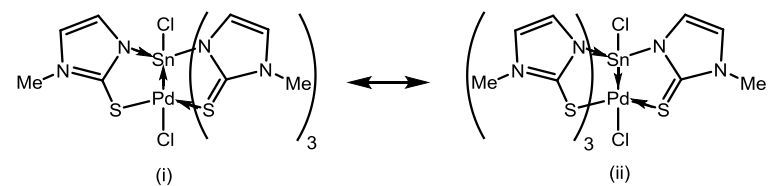

Scheme 8. Possible resonance structures of palladastannatrane 25

Subsequently, Wagler et al. synthesized paddlewheel-type metallosilatranes [CISi $(\mu-\mathrm{mt})_{4} \mathrm{MCl}$ ] of Group 10 transition metal $(\mathrm{M}=\mathrm{Ni}(\mathbf{2 6}), \mathrm{Pd}(\mathbf{2 7}), \mathrm{Pt}(\mathbf{2 8}))$ by the reactions of $\mathrm{Si}(\mathrm{mt})_{4}(\mathrm{Hmt}=$ methylimidazole) with the corresponding bis(triphenylphosphine) dichloride complex $\mathrm{MCl}_{2}\left(\mathrm{PPh}_{3}\right)_{2}(\mathrm{M}=\mathrm{Ni}$, 
Table 6. NLMO data for the M-Si bonds in 26-28.

\begin{tabular}{|c|c|c|c|c|c|c|c|}
\hline \multirow[t]{2}{*}{ Compounds } & \multicolumn{2}{|c|}{ Orbital contribution } & \multicolumn{2}{|c|}{ M hybrid } & \multicolumn{3}{|c|}{ Si hybrid } \\
\hline & M (\%) & $\mathrm{Si}(\%)$ & $\mathrm{s}(\%)$ & $d(\%)$ & s (\%) & $\mathrm{p}(\%)$ & $d(\%)$ \\
\hline $26(\mathrm{M}=\mathrm{Ni})$ & 83 & 13 & 2 & 97 & 37 & 60 & 3 \\
\hline $27(\mathrm{M}=\mathrm{Pd})$ & 84 & 12 & 2 & 98 & 39 & 58 & 2 \\
\hline $28(\mathrm{M}=\mathrm{Pt})$ & 68 & 25 & 17 & 82 & 38 & 60 & 2 \\
\hline
\end{tabular}

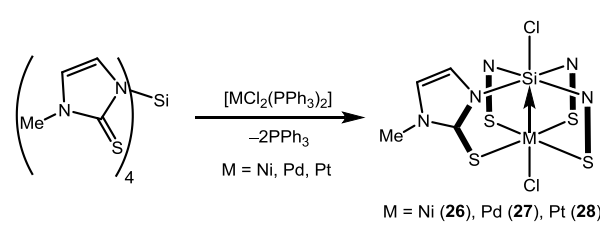

Scheme 9. Synthesis of metallosilatranes 26-28 bearing buttressing methimazolyl bridges.

$\mathrm{Pd}, \mathrm{Pt})$ (Scheme 9). ${ }^{[26]}$ Although these molecular structures in the solid state consist of three independent molecules, these compounds are similar to each other. The $\mathrm{Ni}-\mathrm{Si}$ distance in the predominant molecule is 2.5981(1), and the $\mathrm{Pd}-\mathrm{Si}$ and $\mathrm{Pt}-\mathrm{Si}$ bond distances ranged from $2.527(2)$ to $2.569(1) \AA$ and from $2.447(3)$ to $2.469(2) \AA$, respectively. These distances are comparable to the sum of their covalent radii $(r=1.11(26)$, 1.01-1.03 (27), 0.99-1.00 (28)). The NLMO analysis of 26, 27, and 28 indicated that the contributions of $\mathrm{Si}$ orbitals to $\mathrm{M}-\mathrm{Si}$ bond are significantly larger in $28(25 \%)$ than in $26(13 \%)$ and 27 (12\%) (Table 6). Also, the s character of the metal hybrid is relatively larger in $28(17 \%)$ than in $26(2 \%)$ and $\mathbf{2 7}(2 \%)$ along with the increase in the contributions of Si orbitals to the M-Si bond, suggesting some contributions of the covalent bonding in 28 (description (ii) in Chart 1). The ${ }^{29} \mathrm{Si}$ crosspolarization/magic-angle spinning (CP/MAS) NMR spectra exhibited a signal at $\delta=-188.0(26),-182.6(27)$, and -218.5 (28) ppm, which are very similar to other hexacoordinate silicon compounds with electron-donating main group elements. These spectral data support that the anion fragment $\mathrm{CISi}(\mu-\mathrm{mt})_{4}{ }^{-}$ serves as an eight-electron-donor ligand accepting lone pair electrons from $\mathrm{M}$ through the Lewis acidic Si center.

Notably, the ${ }^{29} \mathrm{Si}$ NMR signals shifted to a higher magnetic field in the order $\mathrm{Pd}<\mathrm{Ni}<\mathrm{Pt}$, which was inconsistent with the strengths of dative $\mathrm{M} \rightarrow \mathrm{Si}$ interactions. They found that spinorbit (SO) relativistic effect significantly affects the ${ }^{29} \mathrm{Si}$ NMR spectra of a series of metallosilatrans $\mathbf{2 6 - 2 8}$, and the SO effect on ${ }^{29} \mathrm{Si}$ NMR chemical shift increased in the order $\mathrm{Pd}<\mathrm{Ni} \ll$ $\mathrm{Pt}^{[27]}$ The large SO effect in the Pt system can be attributed to a large heavy-atom effect on a light atom (HALA), indicating a strong s character (covalent) of bonds between the $\mathrm{M}$ and $\mathrm{Si}$ atoms. This is consistent with the above-mentioned NLMO analysis and large ${ }^{1} \mathrm{~J}_{\mathrm{Pt}-\mathrm{Si}}$ coupling constant $(920 \mathrm{~Hz})$. They also determined the reason why the nickel system showed a relatively higher SO effect than the palladium and concluded that the lower ligand-field splitting in nickel atom played a crucial role. ${ }^{[28]}$ It is very informative that the ${ }^{29} \mathrm{Si} \mathrm{NMR}$ chemical shifts in dative $\mathrm{M} \rightarrow \mathrm{Si}$ interactions are influenced by the SO relativistic effect of different metals rather than the strengths of $\mathrm{M} \rightarrow$ Si interactions.

Sakaki et al. reported a detailed theoretical analysis of platinum-silatrane 28 using DFT calculations. ${ }^{[29]}$ To evaluate the changes in electron distribution induced by $\mathrm{Pt} \rightarrow \mathrm{Si}$ interaction, the electron distribution of silatrane $\mathbf{2 8}$ was compared with that of the $\mathrm{Pt}-\mathrm{ClS}_{4}$ fragment, where the $\mathrm{SiCl}$ moiety in $\mathbf{2 8}$ were removed (Figure $3 \mathrm{a}$ ). In the $\mathrm{Pt}-\mathrm{ClS}_{4}$ fragment, the populations of $d_{z 2}$ and $d_{x 2-y 2}$ orbitals are 1.927 e and 1.170 e, respectively. The significant electron distribution of the $d_{x 2-y 2}$ orbital resulted from the donations from $S$ atoms, and hence the total $d$ orbital population was calculated to be 9.019 e. Thus, it was concluded that the $\mathrm{Pt}$ center in the $\mathrm{Pt}-\mathrm{ClS}_{4}$ fragment has $+\|$ oxidation state ( $d^{8}$ electron configuration), in which the $d_{z 2}$ orbital slightly participates in the coordinate bond. When going from the Pt-ClS 4 fragment to 28 , the $d_{z 2}$ orbital population decreased to $1.640 \mathrm{e}$, indicating that a CT occurred from the $\mathrm{d}_{\mathrm{z} 2}$ orbital to the Si center. Next, the electron distributions between silatrane 28 and the $\mathrm{Si}_{-} \mathrm{CIN}_{4}$ fragment (Figure 3c) were compared. When going from the $\mathrm{Si}-\mathrm{CIN}_{4}$ fragment to the platinum-silatrane, the $\mathrm{p}_{z}$ orbital population of the $\mathrm{Si}$ center significantly increased from 0.470 e to 0.596 e. These changes of electron distributions indicated that $\mathrm{CT}$ occurred from the $\mathrm{Pt}$ $\mathrm{d}_{\mathrm{z} 2}$ orbital to the Si $\mathrm{p}_{\mathrm{z}}$ orbital. If the Pt center has +IV oxidation state, the $P t d_{z 2}$ orbital must be empty in a formal sense. To explain the presence of a large electron distribution in $\mathrm{d}_{\mathrm{z} 2}$ orbital (1.640 e), a considerably strong $\mathrm{CT}$ from $\mathrm{Cl}$ and $\mathrm{Si}$ atoms is required. However, the $\mathrm{Si}$ atom serves as an electron acceptor rather than an electron donor, and the electron distribution of $\mathrm{Cl}$

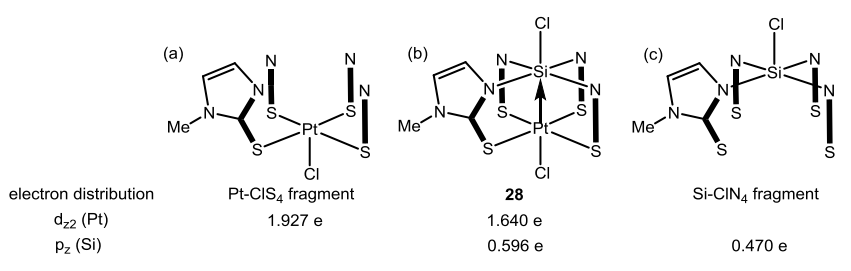

Figure 3. Geometries and electron distributions of platinum-silatrane 28, Pt$\mathrm{ClS}_{4}$ fragment, and $\mathrm{Si}-\mathrm{CIN}_{4}$ fragment.. 
(17.536 e) in 28 indicated that the CT from $\mathrm{Cl}$ atom was less than $0.47 \mathrm{e}$. Therefore, they concluded that the $\mathrm{Pt}-\mathrm{Si}$ bond is formed by the CT from the doubly occupied $\mathrm{d}_{\mathrm{z} 2}$ orbital of $\mathrm{Pt}$ (II) to the empty $p_{z}$ orbital of Si(IV), supporting a strong contribution of description (i) in Chart 1.

Wagler et al. made a guiding principle for the assignment of tin compounds with an ambiguous oxidation state (e.g., divalent or tetravalent configuration). ${ }^{[30]}$ They synthesized pentacoordinate tin compound 29 by the reaction of tin(II) dichloride with $\left[\mathrm{PdCl}_{2}\left(\mathrm{PPh}_{3}\right)_{2}\right]$ and 1-methyl-2mercaptoimidazole (Hmt) (Scheme 10). Subsequent substitution of two chlorine atoms with dianionic tridentate ONN ligand afforded hexacoordinate tin compound 30 . The small Pd-Sn distances (29: 2.5382(1) $\AA$, 30: 2.5443(2) $\AA$ ) and large $J_{\text {Sn-P }}$ coupling constants $\left({ }^{2} J_{117 S n-P},{ }^{2} J_{119 S n-P}\right.$ for $29: 4476 \mathrm{~Hz}$, $4684 \mathrm{~Hz}$; 30: $4387 \mathrm{~Hz}, 4591 \mathrm{~Hz}$ ) indicate the strong interaction between $\mathrm{Pd}$ and $\mathrm{Sn}$ atoms. Three different descriptions, depending on the interpretation, are possible for a dative $\mathrm{Pd} \rightarrow \mathrm{Sn}$ bond in 29 and 30 as shown in Figure 4; (i) $\mathrm{Pd}(\mathrm{II}) \leftarrow \mathrm{Sn}(\mathrm{II})$, (ii) $\mathrm{Pd}(\mathrm{I})-\mathrm{Sn}(\mathrm{III})$, and (iii) $\mathrm{Pd}(0) \rightarrow \mathrm{Sn}(\mathrm{IV})$ interactions. To evaluate the contributions of these descriptions, they also analyzed $\mathbf{2 9}$ and $\mathbf{3 0}$ both spectroscopically and theoretically with $\mathrm{Sn}^{11}$ and $\mathrm{Sn}^{\mathrm{IV}}$ compounds as the references. The ${ }^{119} \mathrm{Sn}$ chemical shifts (29: $\delta=-337 \mathrm{ppm}$ and 30: $\delta=-557$ $\mathrm{ppm})$ are characteristic of penta- and hexacoordinate $\mathrm{Sn}^{\mathrm{IV}}$ complexes, respectively, whereas tetracoordinate tin(II) compounds also potentially exhibit ${ }^{119} \mathrm{Sn}$ signals in a similar region. Hence, they investigated the SO shielding contributions $\left(\sigma^{\mathrm{SO}}\right)$ to the ${ }^{119} \mathrm{Sn}$ chemical shift anisotropy (CSA). The values of $\sigma^{\mathrm{SO}_{11}}, \sigma^{\mathrm{SO}}{ }_{22}$, and $\sigma^{\mathrm{SO}}{ }_{33}$ were comparable in 29 and 30 , which were similar to other reference $\mathrm{Sn}^{\mathrm{VV}}$ compounds. In contrast, the divalent tin compound bearing a formal lone pair clearly showed a different tendency, in which $\sigma^{\mathrm{SO}}{ }_{11}$ and $\sigma^{\mathrm{SO}}{ }_{22}$ were much less than $\sigma^{\mathrm{SO}}{ }_{33}$, probably because of a lower SO shielding effect perpendicular to the formal lone-pair directions. Thus, they concluded that the character of divalent $\mathrm{Sn}^{\prime \prime}$ is absent in the ${ }^{119} \mathrm{Sn} \mathrm{NMR} \mathrm{spectra}$ of $\mathbf{2 9}$ and $\mathbf{3 0}$. The analysis of NCs provided further information. The NC of the tin in 30 (2.16) was much larger than that of the reference divalent tin compound (1.44) and close to that of reference $\mathrm{Sn}^{\mathrm{IV}}$ compound (2.55). Moreover, the natural valence shell populations of the $5 \mathrm{~s}(\mathrm{Sn})$ orbital in $\mathbf{2 9}$ (1.00) and $30(0.83)$ are positioned between those of the references $\mathrm{Sn}^{\mathrm{IV}}(0.57)$ and $\mathrm{Sn}^{\mathrm{III}}(1.16)$ compounds, and much smaller than that of divalent tin compound (1.72). These NBO analyses supported the descriptions of (ii) and (iii) rather than (i). The Mössbauer spectrum also supported the $\mathrm{Sn}^{\mathrm{IV}}$ oxidation state, in which the isomer shift of $29\left(1.48(1) \mathrm{mms}^{-1}\right.$ ) and $\mathbf{3 0}$ $\left(1.14(1) \mathrm{mms}^{-1}\right)$ were close to that of reference $\mathrm{Sn}^{\mathrm{IV}}(0.26(1)$ $\mathrm{mms}^{-1}$ ) compound rather than that of reference $\mathrm{Sn}^{\text {"I }}$ (3.09(1) $\mathrm{mms}^{-1}$ ) compound. These results indicate that the tin centers in 29 and 30 stemming from divalent tin(II) dichloride can be assigned as tetravalent. They also stated that similar electronic structures as $\mathbf{2 9}$ and $\mathbf{3 0}$ were observed in Deelman's compounds $\left[\mathrm{Pd}(\mathrm{Cl})\left(2-\mathrm{PyPPh}_{2}\right)_{2}\left(\mathrm{SnCl}_{2}\right)\right]\left[\mathrm{BF}_{4}\right](31)$ and $[\mathrm{Pd}(\mathrm{Cl})(2-$ $\left.\left.\mathrm{PyPPh}_{2}\right)_{2}\left(\mathrm{SnCl}_{3}\right)\right]$ (32) (2-PyPPh $2=2-$ pyridyldiphenylphsphine), in which the nitrogen donors of the pyridyl groups coordinated to the tin atom (Chart 7). ${ }^{[31]}$ Although stannylene ligands are generally considered as a two-electron donor, their results indicate that penta- and hexacoordinate tin atoms in the presumed stannylene complexes potentially had an oxidative addition of more than +II.

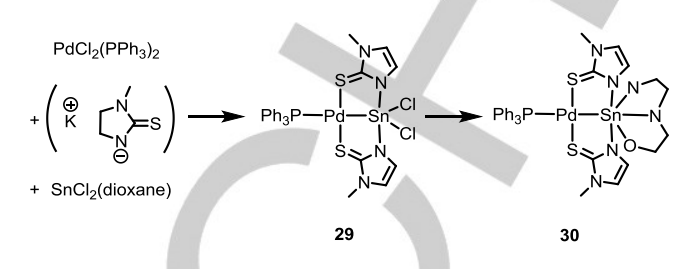

Scheme 10. Preparation of palladium complexes bearing penta- and hexacoordinate tin center using tin(II) dichloride.

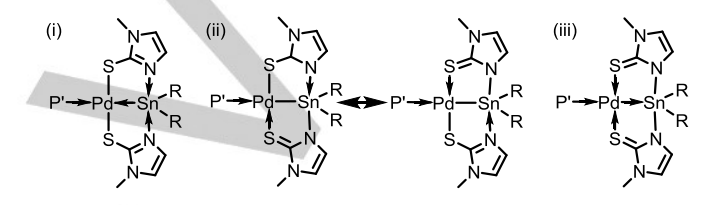

Figure 4. Possible resonance structures of palladium complexes bearing penta- and hexacoordinate tin center. Three descriptions of $\mathrm{Pd}-\mathrm{Sn}$ bonds in 29 and 30. (i) $\mathrm{Pd}(\mathrm{II}) \leftarrow \mathrm{Sn}$ (II), (ii) $\mathrm{Pd}(\mathrm{I})-\mathrm{Sn}$ (III), (iii) $\mathrm{Pd}(0) \rightarrow \mathrm{Sn}(\mathrm{IV})$ interactions.
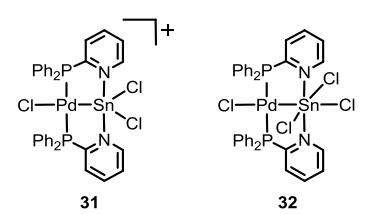

Chart 7. Deelman's palladium complexes 31 and $\mathbf{3 2}$ bearing penta- and hexacoordinate tin center.

\subsection{Metallosilatranes and metallostannatranes consisting of pyridine-2-thionate bridges}

Jambor et al. reported similar findings as those obtained by Wagler and showed that the pentacoordinate tin atoms in the presumed stannylene complexes potentially had an oxidative addition of more than +II. ${ }^{[32]}$ They synthesized platinum complex 33, where the $\mathrm{Pt}$ and $\mathrm{Sn}$ were linked with two pyridine2-thionate fragments (Pt-Sn: 2.4462(4) $\AA, r=0.89$ ). The tin adopted an octahedral geometry, in which the carbon ligand occupied the position trans to the transition metal. The geometric feature provided one covalent $\mathrm{Sn}-\mathrm{C}$ bond $(2.107(7)$ $\AA$ ) and four dative $\mathrm{N} \rightarrow \mathrm{Sn}$ (2.391(5)-2.443(5) $\AA$ ) bonds, allowing the interpretation that the stannylidenium $\left(\mathrm{LSn}^{\text {II }}\right)^{+}$fragment was donated to a $\left[\mathrm{Pt}(\mathrm{pyt})_{2} \mathrm{Cl}\right]^{-}$anion. An NBO analysis indicated that the lone pair of $\mathrm{Sn}^{\prime \prime}$ was shared by the $\mathrm{Sn}$ and $\mathrm{Pt}$ atoms, and that the strong covalent character can be attributed to the sphybridized orbitals on the tin atoms. Further, they commented that $\mathrm{Pt}^{0} \rightarrow \mathrm{Sn}^{\mathrm{IV}}$ description is possible if considering that $\mathrm{Pt}$ has a higher electronegative character than $\mathrm{Sn}$. This conclusion was supported by the highly positive charge on tin $(+1.709)$ and the presence of $\mathrm{Pt} \rightarrow \mathrm{Sn}$ CT interaction $(7.17 \mathrm{kcal} / \mathrm{mol})$. Wagler et al. 
reported more examples of compounds bearing a $\mathrm{M} \rightarrow \mathrm{Sn}$ CT interaction induced by pyridine-2-thiolate for palladium. ${ }^{[33]}$ Palladium complexes $\mathbf{3 4}, \mathbf{3 5}$ and $\mathbf{3 6}$ have two chloro, pyridine2-thiolate, and phenyl substituents, respectively, at the two equatorial positions of the tin center. The Sn-Pd and $\mathrm{Sn}-\mathrm{N}$ distances increased in the order $34<35<36$ (Sn-Pd: 2.5052(2) $\AA$ for 34, 2.5328(2) $\AA$ for 35, 2.5370(2) $\AA$ for 36; Sn-N: 2.287(2) and 2.292(2) $\AA$ for 34, 2.335(2) and 2.386(2) $\AA$ for $35,2.347(2)$ and $2.387(2) \AA$ for 36 ), suggesting that the strengths of these bonds increased with the increase in the Lewis acidity of the tin centers. The NBO analysis indicated a significantly large contribution of $\mathrm{Sn}$ orbital to the $\mathrm{Pd}-\mathrm{Sn}$ bonds (34: $57 \%, 35: 54 \%, 36: 52 \%$ ) and the Sn hybrid orbital of $\mathrm{Pd}-\mathrm{Sn}$ bonds had a high s character $(34: 73 \%, 35: 51 \%, 36$ : $40 \%$ ). The isomer shifts in Mössbauer spectra (34: 1.63(1) $\mathrm{mms}^{-1}$, 35: 1.81(1) $\mathrm{mms}^{-1}, 36: 1.54(1) \mathrm{mms}^{-1}$ ) were strongly correlated to the calculated $5 \mathrm{~s}$ populations $(34: 1.05,35: 1.11$, 36: 0.94), and thus the electron populations were close to $\mathrm{Sn}^{\mathrm{IV}}$ rather than $\mathrm{Sn}^{\prime \prime}$. These data support the strong covalent characters of $\mathrm{Sn}-\mathrm{Pd}$ bonds and the contribution of $\mathrm{Pd}^{0} \rightarrow \mathrm{Sn}^{\mathrm{IV}}$ interaction. They also synthesized dipalladium complex 37 bearing a novel $\mathrm{Pd}-\mathrm{Sn}-\mathrm{Pd}$ linkage, in which the $\mathrm{Pd}-\mathrm{Sn}$ bonds had similar characters as those in 34-36. Although the $\mathrm{Pd}-\mathrm{Sn}$ bonds (2.5946(2) $\AA$ and 2.5945(2) $\AA$ ) in 37 were slightly longer than those in 34-36, the $\mathrm{Sn}$ orbital strongly contributes to the $\mathrm{Pd}-\mathrm{Sn}$ bonds $(48 \%)$, and the $\mathrm{Sn}$ hybrid orbital of the $\mathrm{Pd}-\mathrm{Sn}$ bonds has a large $s$ character $(50 \%)$ in a similar manner as 3436. Furthermore, the isomer shift $\left(2.05(1) \mathrm{mms}^{-1}\right.$ ) and $5 \mathrm{~s}$ population (1.09) are also in the same order, suggesting a strong contribution of $\mathrm{Pd}^{0} \rightarrow \mathrm{Sn}^{\mathrm{IV}} \leftarrow \mathrm{Pd}^{0}$ character to the $\mathrm{Pd}-\mathrm{Sn}-\mathrm{Pd}$ linkage.
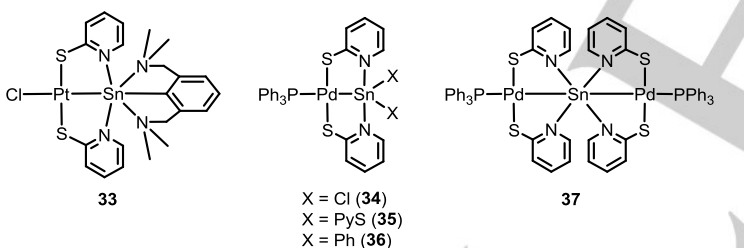

Chart 8. Jambor's platinum complex $\mathbf{3 3}$ and Wagler's palladium complexes 34-37 bearing penta- and hexacoordinate tin centers.

\subsection{Metallosilatranes consisting of buttressing azaindolyl bridges}

Wagler et al. reported a new ligand family of saturated Group 14 compounds, in which 7-azaindol-1-ly bridges were used to construct $\mathrm{M} \rightarrow \mathrm{SiR}_{4}$ interactions. ${ }^{[34]}$ These borane analogs were extensively studied by Owen et al. ${ }^{[9 c]}$ The treatments of $\mathrm{PdCl}_{2} \mathrm{~L}_{2}$ with 7-azaindol-1-ly-substituted silanes $\mathrm{Me}_{(4-n)} \operatorname{SiL}_{n}(n=2,3,4)$ afforded $\mathrm{Me}_{2} \mathrm{Si}(\mu-\mathrm{L})_{2} \mathrm{PdCl}_{2}$ (38), $\mathrm{Me}(\mathrm{L}) \mathrm{Si}(\mu-\mathrm{L})_{3} \mathrm{PdCl}_{2}$ (39), and $(\mathrm{L})_{2} \mathrm{Si}(\mu-\mathrm{L})_{2} \mathrm{PdCl}_{2}(40)$. In all the resulting complexes 38-40, two azaindolyl moieties coordinated to the Pd center, and the other azaindolyl moieties in $\mathbf{3 9}$ and $\mathbf{4 0}$ existed as the substituents on Si without coordination to $\mathrm{Pd}$ (Scheme 11). This is in sharp contrast to the reaction of $\mathrm{SiL}_{4}$-type methylimidazolyl analogs, rapidly providing paddlewheel-type complexes. Thus, the linker moiety led to a significant different reactivity, and a larger steric repulsion of azaindolyl than methylimidazolyl groups probably inhibited the coordination accompanying the dissociation of the $\mathrm{Cl}$ ligand. The $\mathrm{Pd}-\mathrm{Si}$ distances were 3.34 (38), 3.43 (39), and $3.31(40)$, and the $r$ factors were calculated to be $1.34(38)$, 1.37 (39), and $1.32(\mathbf{4 0})$. The bond angles of the Pd-capped tetrahedral face were widened (the sum of the angles were 337.1(38), 330.1(39), and 339.8(40)). These geometric data indicated the presence of $\mathrm{Pd} \rightarrow \mathrm{SiR}_{4}$ interactions. Complex 40 underwent isomerization above $150{ }^{\circ} \mathrm{C}$, affording a paddlewheel-type complex $\mathrm{CISi}(\mu-\mathrm{L})_{4} \mathrm{PdCl}(41)$. The abstraction of a $\mathrm{Cl}$ atom using 1 equiv of $\mathrm{GaCl}_{3}$ followed by recrystallization from acetonitrile also provided a cationic paddlewheel-type complex $\left[\mathrm{ClSi}(\mu-\mathrm{L})_{4} \mathrm{Pd}\left(\mathrm{NCCH}_{3}\right)\right]\left[\mathrm{GaCl}_{4}\right]$ (42), in which the acetonitrile molecule occupied the position trans to the silicon atom. Further, a different cationic paddlewheel compound $\left[\mathrm{CISi}(\mu-\mathrm{L})_{4} \mathrm{Pd}(\mu-\mathrm{Cl}) \mathrm{Pd}(\mu-\mathrm{L})_{4} \mathrm{SiCl}\right]\left[\mathrm{GaCl}_{4}\right]$ (43) bearing a bridging chloride was synthesized from using 0.5 equiv of $\mathrm{GaCl}_{3}$. The geometrical analyses of 41-43 were performed using the crystallographic data of $\mathbf{4 2}$ and $\mathbf{4 3}$ and DFT calculations of $\mathbf{4 1 .}$ The Pd-Si distances in 41-43 (41: $2.62 \AA$, 42: 2.662(2) $\AA$, 43: 2.683(1) $\AA$ ) were slightly longer than the sum of their covalent radii ( $\boldsymbol{r}$ factor; $41: 1.05,42: 1.06,43: 1.07$ ), suggesting the strong interactions between $\mathrm{Pd}$ and $\mathrm{Si}$ atoms. Moreover, the relatively longer $\mathrm{Pd}-\mathrm{Si}$ distances in cationic systems (42 and 43) can be attributed to the relatively weak Lewis acidity of the metal center. The NLMO analysis of $\mathbf{4 0}, \mathbf{4 1}$, and $\mathbf{4 2}$ enabled a more quantitative analysis of the different donor strengths of the $\mathrm{Pd}$ center (Table 7). The contributions of Si orbitals to the $\mathrm{Pd}-\mathrm{Si}$ bond increased in the order $\mathbf{4 0}(1 \%)<\mathbf{4 2}(8 \%)<\mathbf{4 1}$ (15\%), which is apparently consistent with the strengths of $\mathrm{Pd}-\mathrm{Si}$ interactions. A high $\mathrm{d}$ character of the $\mathrm{Pd}$ hybrid remained unchanged among the three, whereas the $s$ character of the Si hybrid increased in the order $\mathbf{4 0}(8 \%)<\mathbf{4 2}(28 \%)<$ $41(45 \%)$ with an increase in donor-acceptor interactions, suggesting relatively a stronger contribution of covalent bonding (description (ii) in Chart 1).

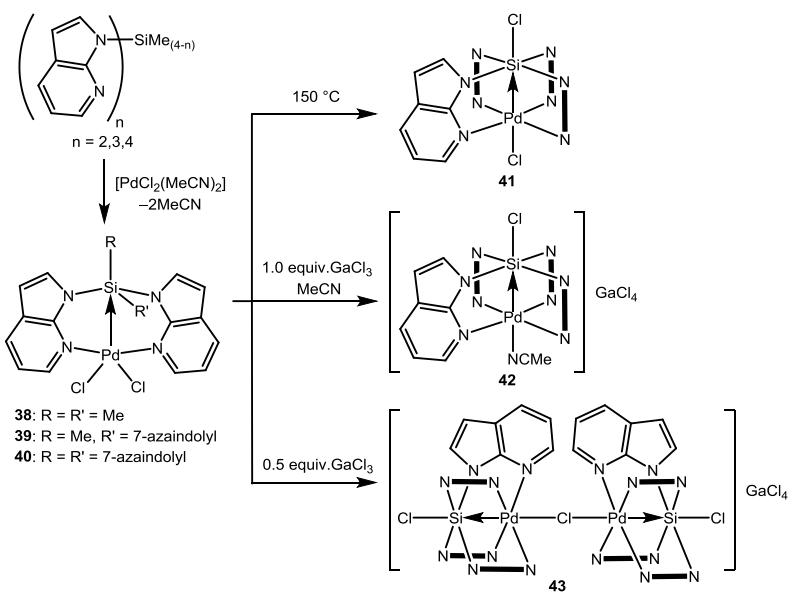

Scheme 11. Preparation of paddlewheel-type palladasilatranes consisting of azaindolyl bridges. 
Table 7. NLMO data for the Pd-Si bonds in $\mathbf{4 0 - 4 2}$

\begin{tabular}{|c|c|c|c|c|c|c|c|}
\hline \multirow[t]{2}{*}{ Compounds } & \multicolumn{2}{|c|}{ Orbital contribution } & \multicolumn{2}{|c|}{ M hybrid } & \multicolumn{3}{|c|}{ Si hybrid } \\
\hline & $\mathrm{Pd}(\%)$ & Si (\%) & $\mathrm{s}(\%)$ & $d(\%)$ & $\mathrm{s}(\%)$ & $\mathrm{p}(\%)$ & $d(\%)$ \\
\hline 40 & 98 & 1 & 2 & 98 & 8 & 89 & 3 \\
\hline 41 & 83 & 15 & 3 & 97 & 45 & 54 & 1 \\
\hline 42 & 89 & 8 & 3 & 97 & 28 & 69 & 3 \\
\hline
\end{tabular}

\subsection{Z-type germane ligand without linker moiety}

Kano and Kawashima reported an anionic iron complex $\mathrm{Na}\left[\mathrm{Rf}_{2} \mathrm{GeFp}\right]$ (44) (Rf = $-\mathrm{C}_{6} \mathrm{H}_{3}-4-\mathrm{CH}_{3}-2-\mathrm{C}\left(\mathrm{CF}_{3}\right)_{2} \mathrm{O}-, \quad \mathrm{Fp}=$ $\mathrm{Fe}(\mathrm{Cp})(\mathrm{CO})_{2}$ ) featuring a pentacoordinate germanium ligand without a linker moiety (Scheme 12). ${ }^{[35]} \mathrm{Na}\left[\mathrm{Rf}_{2} \mathrm{GeFp}\right]$ was obtained by the reaction of spirogermane bearing two sets of the bidentate ligand Rf, with highly nucleophilic NaFp. The strong electron donation of the iron moiety is important in forming the $\mathrm{Fe}-\mathrm{Ge}$ bond, and the oxidation of $\mathrm{Na}\left[\mathrm{Rf}_{2} \mathrm{GeFp}\right]$ cleaved the $\mathrm{Fe}-\mathrm{Ge}$ bond to afford $\mathrm{Rf}_{2} \mathrm{Ge}$. The corresponding ammonium salt, $\left[\mathrm{PhCH}_{2} \mathrm{NMe}_{3}\right]\left[\mathrm{Rf}_{2} \mathrm{GeFp}\right]$ (45), was also obtained. One of the marked features in $\mathbf{4 4}$ and $\mathbf{4 5}$ is the very short Ge-Fe distances (2.404(2) and 2.4065(7)), which are shorter than even the sum of their covalent radii $(r=0.95$ (44 and 45)). The NBO analysis of the Ge-Fe $\sigma$-bond showed an $\mathrm{sp}^{2}$ hybrid orbital on germanium. This is because the iron in $\mathbf{4 4}$ occupies one of the equatorial positions of the trigonal pyramidal $\mathrm{Ge}$ center. Therefore, the $\mathrm{Ge}$ orbitals strongly

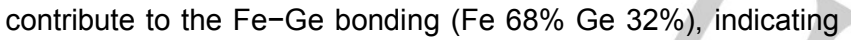
that the lighter $\mathrm{Ge}$ relative to $\mathrm{Sn}$ can also form strong $\mathrm{M}-\mathrm{Ge}$ bonds with a significant covalent character. Although the $\pi$ back donation from the iron to the antibonding orbital of the apical three-center four-electron bond would also contribute to a strong interaction between the $\mathrm{Fe}$ and $\mathrm{Ge}$ in $\mathbf{4 4}$ and $\mathbf{4 5}$, a significantly short $\mathrm{Fe}-\mathrm{Ge}$ distance and relatively large contribution of $\mathrm{Ge}$ orbital implied some contributions of extreme (ii) in chart 1.

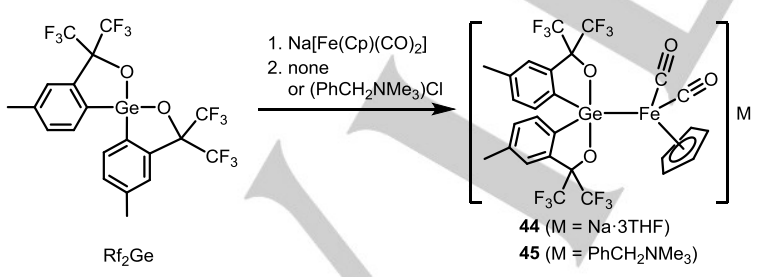

Scheme 12. Preparation of anionic iron complexes bearing a pentacoordinate germanium ligand.

The valences of $\mathrm{Fe}$ and $\mathrm{Ge}$ were experimentally investigated by XPS and SQUID measurements. The XPS of $\mathbf{4 5}$ showed that the binding energy of $\mathrm{Ge} 2 p$ lied between those of bare iron with zero valence $(707.4 \mathrm{eV})$ and $\left[\mathrm{FeCp}(\mathrm{CO})_{2}\right]_{2}$ with monovalence (708.5 eV). Further, a low magnetic susceptibility in the SQUID measurement $\left(4.02 \times 10^{-4} \mathrm{~cm}^{3} / \mathrm{mol}\right)$ eliminated the possibility of mono- and trivalent iron center. Hence it was concluded that the Fe had zero valence. The binding energy of $\mathrm{Ge} 3 \mathrm{~d}$ lied between those of $\mathrm{Ph}_{4} \mathrm{Ge}$ and $\mathrm{GeO}_{2}$, indicating tetravalent germanium. The spectroscopic measurements supported the description of $\mathrm{Fe}(0) \rightarrow \mathrm{Ge}(\mathrm{IV})$. In other words, the main contribution to the $\mathrm{Fe}-\mathrm{Ge}$ bonding in $\mathbf{4 5}$ is still attributed to description (i) in Chart 1.

\subsection{Carbene-cobalt complexes bearing a pentacoordinate silicon ligand}

More recently, Deng et al. reported cobalt complexes $46 a$ and $46 \mathrm{~b}$ with a pentacoordinate silicon ligand (Scheme 13). ${ }^{[36]}$ The Co-Si distances of 46a (2.275(1) $\AA$ and 46b (2.267(1) $\AA$ ) were significantly shorter than the sum of their covalent radii $(2.37 \AA)$. Cobalt complex $\left[\left(\mathrm{CSi}^{\mathrm{R}}\right) \mathrm{Co}(\mathrm{IMes})\right](47)$ bearing a silyl$\mathrm{NHC}$ ligand reacted with 1 equiv of 2-pyridone, affording cobalt complex 48 bearing a tridentate carbene-silyl-pyridine ligand. Further reaction of $\mathbf{4 8}$ with 2-pyridone resulted in the formation of 46 . Complex 46 was also prepared by the reaction of 47 with 3 equiv of 2-pyridone. DFT calculations indicated that the oxidation of 46 induced the cleavage of the Co-Si $\sigma$-bond, resulting in a four-coordinate silicon complex, even although experimental evidence was unavailable because of the low stability of the oxidation product. This indicates that the electronic structure rather than the ligand geometry requirement plays an important role in the formation of the Co-Si bond. In 46, the cobalt center and two carbon atoms occupied the equatorial positions and the two oxygen atoms occupied the apical positions. The three-center four-electron bond nature of the $\mathrm{O}-\mathrm{Si}-\mathrm{O}$ was supported by the long $\mathrm{Si}-\mathrm{O}$ bonds (1.863(3) and $1.868(2) \AA$ on average in $46 \mathbf{a}$ and $46 \mathrm{~b}$, respectively), which are comparable to five coordinate alkoxysilane. These geometric features are similar to those of $\mathrm{Ge}$ compounds 44 and $\mathbf{4 5}$ with a very short $\mathrm{Fe}-\mathrm{Ge}$ distance. The NBO analysis of 46a indicated that $\mathrm{Co}-\mathrm{Si} \sigma$-bond consisted of a $\mathrm{Si} \mathrm{sp}$ hybrid orbital (s 52\%, p 48\%) and the 3d orbital of Co atom, and the s character of the Si orbital was larger than that of the Ge orbital in 44. Further, the contributions of the Co and Si orbitals were calculated to be $55 \%$ and $43 \%$, respectively, and the Si orbital contributed to the formation of $\mathrm{Co}_{-} \mathrm{SiR}_{4}$ bond more than the $\mathrm{Ge}$ orbital in 44. Moreover, the contribution of electron acceptor saturated Group 14 ligands was larger than other $M \rightarrow S_{i R}$ systems. For example, even the very strong $\mathrm{M} \rightarrow \mathrm{Si}$ bonds in 
[CISi $\left.(m-\mathrm{mt})_{4} \mathrm{MCl}\right](\mathrm{M}=\mathrm{Ni}, \mathrm{Pd}$, and $\mathrm{Pt})$ have lower contribution of Si orbitals $(13 \%, 12 \%$, and $25 \%$, respectively). These results encouraged them to advocate the covalent nature of $M-E_{4}$ bond. Their claim was supported by the fact that only three $3 \mathrm{~d}$ lone pairs existed on the cobalt center. In other words, the formal oxidation state of cobalt and silicon can be assigned to $\mathrm{Co}(\mathrm{III})$ and $\mathrm{Si}(\mathrm{II})$ (description (ii) in Chart 1).

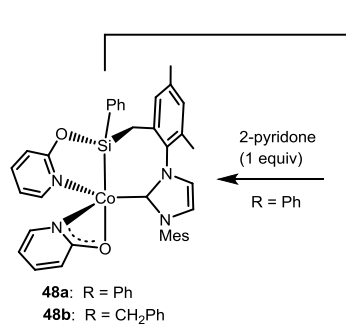

2-pyridone

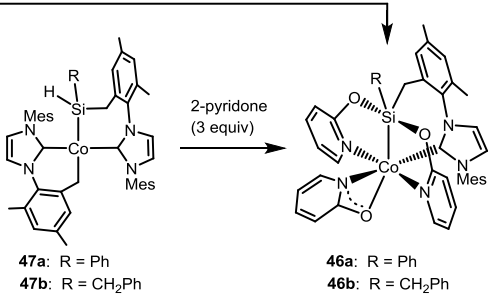

Scheme 13. Preparation of carbene-cobalt complexes bearing a pentacoordinate silicon ligand.

\section{Bond activation reactions following the formation of a dative $\mathrm{I} \rightarrow \mathrm{E}$ bond $(\mathrm{E}=\mathrm{Si}, \mathrm{Ge})$}

\subsection{Iridium-hydride-mediated cleavage of $\mathrm{Si}-\mathrm{F}$ and $\mathrm{Ge}-\mathrm{F}$ bonds}

As mentioned above, diphosphine-fluorosilane and triphosphine-fluorosilane connected using o-phenylene linkers mimicked $\mathrm{S}_{\mathrm{N}} 2$-type intermediates. These interesting species prompted us to investigate the reactivity of fluorosilanes activated using transition metals. ${ }^{[37-39]}$ From our previous study on the reaction of iridium hydride $\operatorname{Ir}(\mathrm{H})(\mathrm{CO})\left(\mathrm{PPh}_{3}\right)_{3}$ (49) with diphosphine-borane, affording a borane iridium complex with significant $\mathrm{Ir} \rightarrow \mathrm{B}$ interaction, ${ }^{[12 \mathrm{c}]}$ we expected that dative $\mathrm{Ir} \rightarrow \mathrm{Si}$ interactions would be similarly formed through the reactions of transition-metal complexes with bis(2diphenylphosphinophenyl)difluorosilane. Moreover, we considered the possibility that the presence of a hydride would induce subsequent irreversible bond activation reactions accompanied with the formation of HF gas. Therefore, iridium hydride 49 was found to cleave the $\mathrm{Si}-\mathrm{F}$ bond in bis(2diphenylphosphinophenyl)difluorosilane, affording silyl complex 50 and HF gas (Scheme 14). The DFT calculations supported that a hypervalent silicon species $\mathrm{A} 1$ with a dative $\mathrm{Ir} \rightarrow \mathrm{Si}$ interaction was the key intermediate of Si-F bond cleavage (Figure 5), in which the Si-F bond trans to the Ir center was elongated to $1.714 \AA$ than $\mathrm{Ph}_{2} \mathrm{SiF}_{2}(1.618 \AA)$. Considering the elongation of the $\mathrm{Si}-\mathrm{F}$ bond in the intermediate, we first investigated the $S_{N} 2$-type reactions starting from several possible intermediates including A1. However, the fluorine dissociation modeled by the elongation of the apical Si-F bond did not provide any stable species, even when the solvent effect (PCM model) was considered. Hence, the $\mathrm{S}_{\mathrm{N}} 2$-type reaction mechanism was ruled out. The Berry pseudorotation of the pentacoordinate Si atom in $\mathbf{A} 1$ occurred with a low Gibbs activation energy $\left(\Delta G^{0 \ddagger}=0.4 \mathrm{kcal} / \mathrm{mol}\right)$ to place the $\mathrm{Ir}$ fragment in the equatorial position and one $\mathrm{F}$ atom in the apical position (Table 8). Subsequent Si-F bond activation afforded the silyl complex and HF through $\sigma$-bond metathesis. The Gibbs activation energy of $\mathrm{Si}-\mathrm{F}$ activation step was calculated to be $14.0 \mathrm{kcal} / \mathrm{mol}$, which was consistent with the experimental result that the reaction occurred under mild conditions. The NBO analysis of the charges on the intermediates and transition states explained the reason why the extremely strong $\mathrm{Si}-\mathrm{F}$ bond in fluorosilane was cleaved even under mild

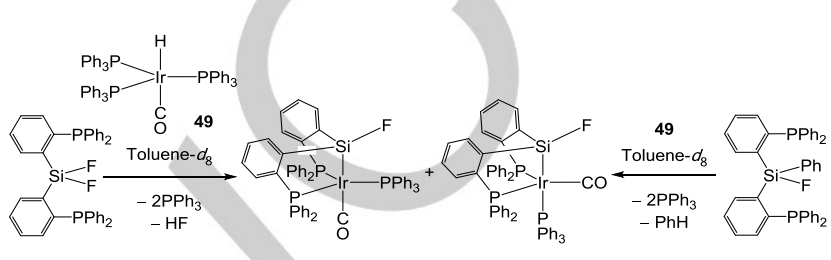

$84 \%$

50-mer $\quad(17: 83) \quad 50-f a c \quad>99 \%$

Scheme 14. Si-F and $\mathrm{Si}-\mathrm{C}_{\mathrm{Ph}}$ activation of $\left\{\mathrm{O}-\left(\mathrm{Ph}_{2} \mathrm{P}\right) \mathrm{C}_{6} \mathrm{H}_{4}\right\}_{2} \mathrm{Si}(\mathrm{F})_{2}$ and $\{0-$ $\left.\left(\mathrm{Ph}_{2} \mathrm{P}\right) \mathrm{C}_{6} \mathrm{H}_{4}\right\}_{2} \mathrm{Si}(\mathrm{F})(\mathrm{Ph})$, leading to the silyl complex $\mathbf{5 0}$
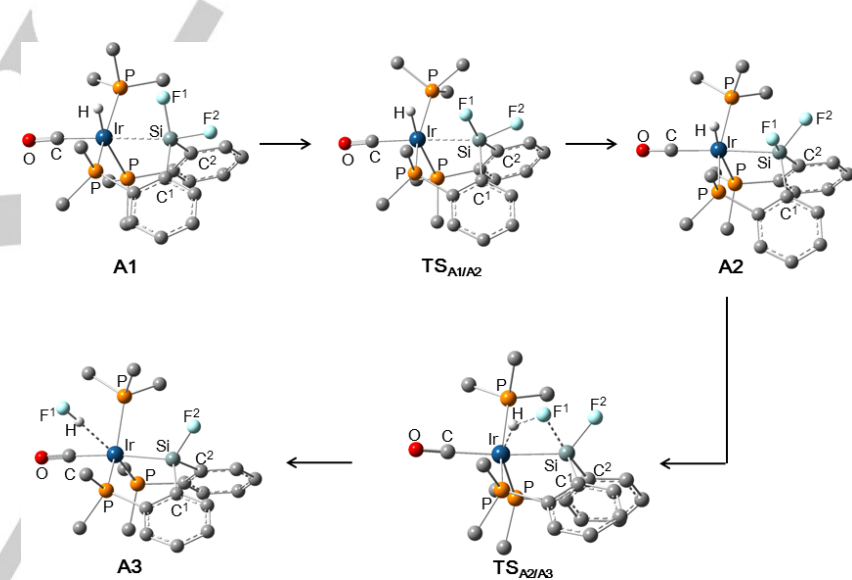

Figure 5. Geometry change in Si-F bond activation with an iridium hydride.
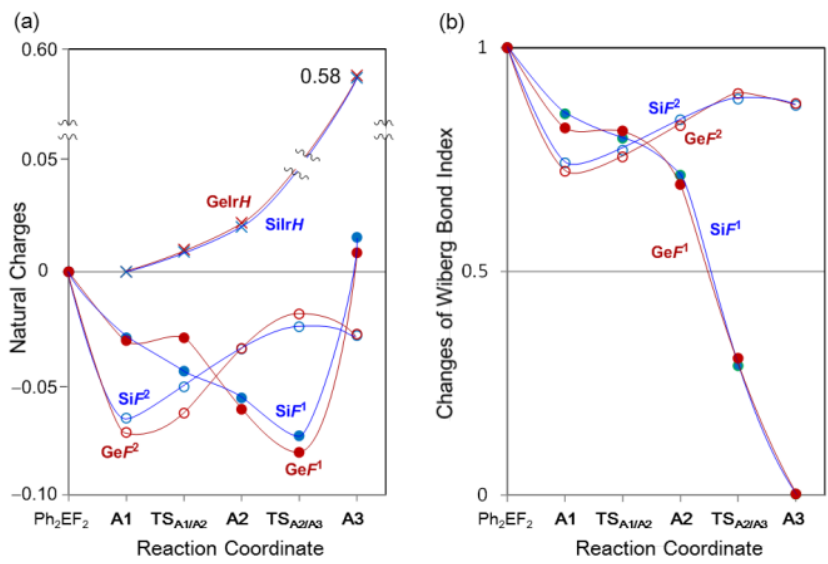

Figure 6. (a) Changes in the NBO charges on $F^{1}, F^{2}$, and $\mathrm{H}$ atoms. (b) Changes in the WBls of $E-F^{1}$ and $E-F^{2} \sigma$-bonds $(E=S i, G e)$. The WBIs are 
relative to those of $\mathrm{Ph}_{2} \mathrm{EF}_{2}$. The $\mathrm{NCs}$ on the $\mathrm{F}$ atoms and $\mathrm{H}$ ligand are relative to those of $\mathrm{Ph}_{2} \mathrm{EF}_{2}$ and $\mathbf{A} 1$, respectively.

Table 8. Gibbs energy changes in the $\sigma$-bond metathesis (kcal/mol)

\begin{tabular}{lccccc}
\hline & A1 & TS $_{\text {A1/A2 }}$ & A2 & TS $_{\text {A2/A3 }}$ & A3 \\
\hline$\Delta G^{0}(\mathrm{E}=\mathrm{Si})$ & 0.0 & 0.4 & -3.0 & 12.1 & -3.8 \\
$\Delta G^{0}(\mathrm{E}=\mathrm{Ge})$ & 0.0 & 1.8 & -0.5 & 8.9 & -8.8 \\
\hline
\end{tabular}

conditions (Figure 6). In A1, the atomic charges of $\mathrm{F}^{2}$ became significantly negative because of $C T$ interaction from $d(I r)$ to $\sigma^{*}(\mathrm{Si}-\mathrm{F})$ orbital. In contrast to $\mathbf{A} 1, \mathbf{A} 2$ had a significantly negative apical $\mathrm{F}^{1}$ atom because of Berry pseudorotation. During the Berry pseudorotation, the $\mathrm{H}$ atom on the Ir center became positively charged in the order $\mathrm{A} 1<\mathrm{TS}_{\mathrm{A} 1 / \mathrm{A} 2}<\mathrm{A} 2$, because of the CT from the Ir center to the $\mathrm{F}_{2} \mathrm{SiAr}_{2}$ moiety. Therefore, the $\mathrm{Ir} \rightarrow \mathrm{Si}$ interaction provided a positively charged $\mathrm{H}$ atom and a negatively charged $\mathrm{F}$ atom. This polarization electrostatically helped the coupling of the $\mathrm{H}$ on the $\mathrm{Ir}$ atom with the $\mathrm{F}$ on the $\mathrm{Si}$.

In typical $\sigma$-bond metathesis between $\mathrm{M}\left(\delta^{+}\right)-\mathrm{X}^{1}\left(\delta^{-}\right)$and $\mathrm{E}\left(\delta^{+}\right)-\mathrm{X}^{2}\left(\delta^{-}\right) \quad \sigma$-bonds, the positively charged $\mathrm{M}$ center approaches the $X^{2}$ atom, and the negatively charged $X^{1}$ approaches the $E$ atom (Chart 9), inducing electron flows from $X^{2}$ to $M$ and from $X^{1}$ to $E{ }^{2}$ This situation is opposite to that of the $\mathrm{Si}-\mathrm{F}$ bond activation with an iridium hydride, which is probably an important factor in the unprecedented Si-F bond activation of fluorosilane $\mathrm{R}_{n} \mathrm{SiF}_{(4-n)}$.

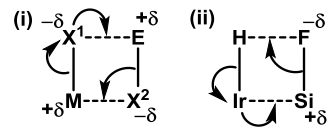

Chart 9. Electron flows in general $\sigma$-bond metathesis (i) and $\mathrm{Si}-\mathrm{F}$ bond activation using iridium hydride (ii).

The observation of an inverse electron flow prompted us to investigate the $\mathrm{Ge}-\mathrm{F}$ bond activation in bis(2diphenylphosphinophenyl)difluorogermane. This is because the stronger electron acceptor ability of $\mathrm{Ge}$ than $\mathrm{Si}$ potentially induces a larger electron flow, leading to unprecedented transition-metal-mediated $\mathrm{Ge}-\mathrm{F} \quad \sigma$-bond activation. ${ }^{[40]}$ The reaction of 49 with $\left\{0-\left(\mathrm{Ph}_{2} \mathrm{P}\right) \mathrm{C}_{6} \mathrm{H}_{4}\right\}_{2} \mathrm{GeF}_{2}$ afforded germyl complex 51 via $\mathrm{Ge}-\mathrm{F}$ bond activation (Scheme 15). Interestingly, $\mathrm{Ge}-\mathrm{F}$ bond cleavage occurred in the reaction of $\left\{0-\left(\mathrm{Ph}_{2} \mathrm{P}\right) \mathrm{C}_{6} \mathrm{H}_{4}\right\}_{2} \mathrm{Ge}(\mathrm{F})(\mathrm{Ph})$ with 49, affording germyl complex 52. This is in marked contrast to the reaction of silicon analog $\{0-$ $\left.\left(\mathrm{Ph}_{2} \mathrm{P}\right) \mathrm{C}_{6} \mathrm{H}_{4}\right\}_{2} \mathrm{Si}(\mathrm{F})(\mathrm{Ph})$ with 49 , in which the $\mathrm{Si}-\mathrm{C}_{\mathrm{Ph}}$ bond was exclusively cleaved. The DFT calculations using model compounds indicated that the $\sigma$-bond metathesis of $\mathrm{Ge}-\mathrm{F} \sigma$ bond with $\mathrm{Ir}-\mathrm{H} \sigma$-bond proceeded with a significantly lower Gibbs activation energy $(9.4 \mathrm{kcal} / \mathrm{mol})$ than the $\mathrm{Si}-\mathrm{F} \sigma$-bond $(15.1 \mathrm{kcal} / \mathrm{mol}$ ) (Table 8). To investigate the origin of the low Gibbs activation energy of the Ge-F bond activation, we investigated the variations in the WBI of $\mathrm{Ge} / \mathrm{Si}-\mathrm{F}$ bonds along the reaction profile (Figure $6 b$ ). In $\mathbf{A} 1$, the $\mathrm{WBI}$ is smaller for $\mathrm{Ge}-\mathrm{F}^{2}$ than $\mathrm{Ge}-\mathrm{F}^{1}$, because $\mathrm{F}^{1}$ and $\mathrm{F}^{2}$ occupy the equatorial and apical positions, respectively. This situation is reversed in A2. The apical $\mathrm{Ge}-\mathrm{F}^{1}$ bond, which is weaker than the equatorial $\mathrm{Ge}-\mathrm{F}^{2}$ bond according to $\mathrm{WBI}$, is cleaved upon the $\sigma$-bond metathesis with the $\mathrm{Ir}-\mathrm{H}$ bond. The tendency of the changes in $\mathrm{WBI}$ in the $\mathrm{Si}$ system is similar to that in the $\mathrm{Ge}$ systems, but it should be noted that the $\mathrm{Ge}-\mathrm{F}^{2}$ bond in $\mathrm{A} 1$ and the $\mathrm{Ge}-\mathrm{F}^{1}$ bond in $\mathbf{A} \mathbf{2}$ are apparently more weakened than the corresponding Si-F $\sigma$-bonds in $\mathrm{Si}$ analogs. This indicates that a stronger $\mathrm{Ir} \rightarrow \mathrm{Ge}$ donation weakens the $\mathrm{Ge}-\mathrm{F} \sigma$-bond more efficiently than the Si system. The NBO charge analysis of the reaction intermediates and transition states showed that the changes in the atomic charges on $\mathrm{F}$ by inverse electron flow were smaller with $\mathrm{Si}-\mathrm{F} \sigma$-bond activation than with $\mathrm{Ge}-\mathrm{F} \sigma$ bond activation. A more negative atomic charge on $\mathrm{F}^{1}$ in $\mathbf{A} 2$ should make the formation of HF more electrostatically facile, which is an important factor for a lower Gibbs activation energy. This unexpected selectivity was probably explained by the stronger $\sigma$-electron acceptor ability of fluorogermane than fluorosilane, leading to the efficient weakening of the E-F bond and the facile coupling of $\mathrm{H}$ and $\mathrm{F}$.

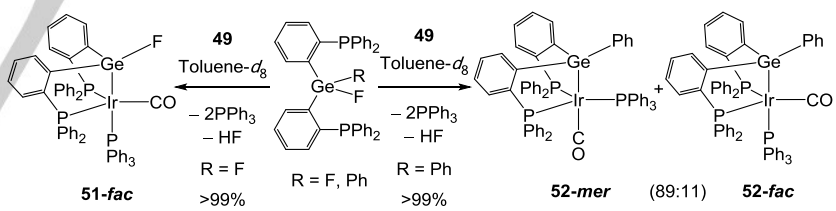

Scheme 15. Ge-F activation of $\left\{0-\left(\mathrm{Ph}_{2} \mathrm{P}\right) \mathrm{C}_{6} \mathrm{H}_{4}\right\}_{2} \mathrm{Ge}(\mathrm{F})(\mathrm{R})(\mathrm{R}=\mathrm{F}, \mathrm{Ph})$ at iridium..

\subsection{Iridium-hydride-mediated cleavage of $\mathrm{Si}-\mathrm{Cl}$ and $\mathrm{Ge}-\mathrm{Cl}$ bonds}

Because the activation of $\mathrm{Si}-\mathrm{F}$ and $\mathrm{Ge}-\mathrm{F}$ bonds was achieved under low polarity of solvents such as benzene and toluene, we experimentally and theoretically investigated the possibility of $\mathrm{Si}-\mathrm{Cl}$ and $\mathrm{Ge}-\mathrm{Cl}$ bond activation using the same strategy. ${ }^{[41]}$ Transition-metal-mediated $\mathrm{Si}-\mathrm{Cl}^{[42]}$ and $\mathrm{Ge}-\mathrm{Cl}^{[43]}$ bond cleavages are limited except for some pioneering studies, and mechanistic information from theoretical studies is particularly scarce. ${ }^{[42 i]}$ The difficulty of incorporating solvation effects in electronic structure calculations often prevents the theoretical studies on $\mathrm{S}_{\mathrm{N}} 2$-type reactions $\left(\mathrm{S}_{\mathrm{N}} 2\right.$-type reactions strongly depend on solvation). Therefore, the reactions in a low polarity solvent enable to simplify the model compounds without using 
an explicit solvent molecule. The reactions of \{0$\left.\left.\mathrm{Ph}_{2} \mathrm{P}\right) \mathrm{C}_{6} \mathrm{H}_{4}\right\}_{2} \mathrm{Si}(\mathrm{Cl})_{2}$ with 49 occurred in a toluene solution, affording the expected $\mathrm{Si}-\mathrm{Cl}$ bond activation products 53-mer and 53-fac, namely, the chloro analogs of 50-mer and 50-fac, and the dichloro(silyl)iridium(III) complex $\{0-$ $\left.\left(\mathrm{Ph}_{2} \mathrm{P}\right) \mathrm{C}_{6} \mathrm{H}_{4}\right\}_{2}(\mathrm{Cl}) \mathrm{Si}\left\{\mathrm{Ir}(\mathrm{Cl})_{2}(\mathrm{CO})\right\}(\mathbf{5 4})$ (Scheme 16). The yields of 53-fac, 53-mer, and $\mathbf{5 4}$ were estimated from the NMR data to be $32 \%, 12 \%$, and $56 \%$, respectively. Complex $\mathbf{5 4}$ was obtained by further reaction of 53 with the $\mathrm{HCl}$ formed, which was confirmed by treating the reaction mixture of $\mathbf{5 3}$ and $\mathbf{5 4}$ with $\mathrm{HCl}$. Similarly, the reaction of 49 with \{0$\left.\left(\mathrm{Ph}_{2} \mathrm{P}\right) \mathrm{C}_{6} \mathrm{H}_{4}\right\}_{2} \mathrm{Ge}(\mathrm{Cl})_{2}$ produced $\mathrm{Ge}-\mathrm{Cl}$ bond activation products 55-fac, 55-mer, and 56, and their yields were estimated to be $33 \%, 8 \%$, and $59 \%$, respectively. Moreover, it was confirmed that the addition of $\mathrm{HCl}$ to a mixture of $\mathbf{5 5}$ and $\mathbf{5 6}$ resulted in the selective conversion of $\mathbf{5 5}$ into $\mathbf{5 6}$. DFT calculations were performed for $\mathrm{Si}-\mathrm{Cl}$ and $\mathrm{Ge}-\mathrm{Cl}$ bond activation on various pathways starting from several intermediates. The results indicate that $\mathrm{Si}-\mathrm{Cl}$ and $\mathrm{Ge}-\mathrm{Cl}$ bonds were cleaved via $\mathrm{S}_{\mathrm{N}} 2$-type reactions as shown in Figure 7. The $\mathrm{S}_{\mathrm{N}}$ 2-type pathways starting from $\left\{0-\left(\mathrm{Me}_{2} \mathrm{P}\right) \mathrm{C}_{6} \mathrm{H}_{4}\right\}_{2}(\mathrm{Cl})_{2} \mathrm{E}\left\{\mathrm{Ir}(\mathrm{H})(\mathrm{CO})\left(\mathrm{PMe}_{3}\right)\right\}$ (B1) (E = Si, Ge) occurred even in the gas phase with very low $\Delta G^{0 \neq}(\mathrm{Si}: 2.6$ $\mathrm{kcal} / \mathrm{mol}, \mathrm{Ge}: 3.3 \mathrm{kcal} / \mathrm{mol})$ and negative $\Delta G^{0}(\mathrm{Si}:-5.0 \mathrm{kcal} / \mathrm{mol}$, Ge: $-2.0 \mathrm{kcal} / \mathrm{mol}$ ) values, affording intermediate B2, in which a free chloride anion dissociated from the $\mathrm{Si}(\mathrm{Ge})$ atom remains with the product complex because of electrostatic interactions.
The solvation effect (toluene) strongly stabilizes the transition states (Si: $-3.7 \mathrm{kcal} / \mathrm{mol}, \mathrm{Ge}:-4.0 \mathrm{kcal} / \mathrm{mol}$ ) and products (Si: $-18.0 \mathrm{kcal} / \mathrm{mol}$, Ge: $-13.5 \mathrm{kcal} / \mathrm{mol}$ ) as expected, and the Gibbs energies became lower in the transition state than that in B1. Hence, in a toluene solution, $S_{N} 2$-type additions starting from B1 occur without any barrier after the formation of B1. These results are the first evidence for a transition-metal-mediated $\mathrm{E}-\mathrm{Cl}$ activation $\left(\mathrm{E}=\mathrm{Si}, \mathrm{Ge}\right.$ ) achieved via an $\mathrm{S}_{\mathrm{N}} 2$-type reaction. As mentioned above, $\mathrm{E}-\mathrm{F}$ bond activation, unlike $\mathrm{E}-\mathrm{Cl}$ bond activation, occurs via $\sigma$-bond metathesis. The difference between $\mathrm{E}-\mathrm{F}$ and $\mathrm{E}-\mathrm{Cl}$ bond activation can be attributed to the fact that the $\mathrm{E}-\mathrm{Cl}$ bond is much weaker than the $\mathrm{E}-\mathrm{F}$ bond, and the $\mathrm{H}-\mathrm{F}$ bond is much stronger than the $\mathrm{H}-\mathrm{Cl}$ bond.

In contrast, as far as the activation of $\mathrm{E}-\mathrm{C}$ bonds in $\{0$ $\left.\left(\mathrm{Ph}_{2} \mathrm{P}\right) \mathrm{C}_{6} \mathrm{H}_{4}\right\}_{2} \mathrm{E}(\mathrm{F})(\mathrm{Ph})(\mathrm{E}=\mathrm{Si}, \mathrm{Ge})$ is concerned, concerted oxidative addition followed by reductive elimination is the lowest activation pathway. In other words, the activation of less polar and relatively weaker $\mathrm{E}-\mathrm{C} \sigma$-bonds can be more readily achieved through oxidative addition than $\sigma$-bond metathesis or $\mathrm{S}_{\mathrm{N}} 2$-type reaction. Notably, despite $\sigma$-bond activations induced by the two rigid phosphine buttresses, the $\mathrm{E}-\mathrm{F}, \mathrm{E}-\mathrm{Cl}$, and $\mathrm{E}-\mathrm{C}$ $\sigma$-bond activations follow a different mechanism; the $\mathrm{E}-\mathrm{F}, \mathrm{E}-\mathrm{Cl}$, and $\mathrm{E}-\mathrm{C} \sigma$-bond activation reactions occur via $\sigma$-bond metathesis, $\mathrm{S}_{\mathrm{N}} 2$-type reaction, and concerted oxidative addition, respectively. The difference in the mechanistic pathways can be attributed to the polarity and strength of the $\mathrm{E}-\mathrm{X} \sigma$-bonds $(\mathrm{X}$

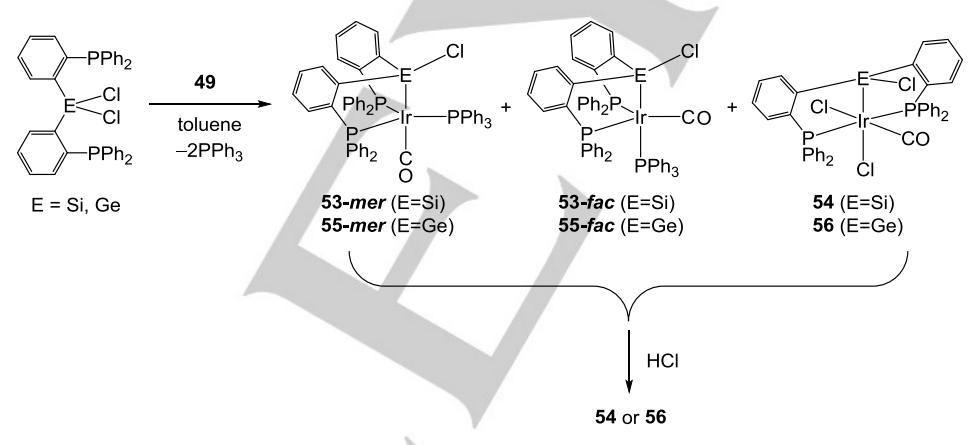

Scheme 16. $\mathrm{E}-\mathrm{Cl}$ bond activation in $\left\{\left(\mathrm{o}-\mathrm{Ph}_{2} \mathrm{P}\right) \mathrm{C}_{6} \mathrm{H}_{4}\right\}_{2} \mathrm{E}(\mathrm{Cl})_{2}(\mathrm{E}=\mathrm{Si}, \mathrm{Ge})$ in the reaction with 49 and the subsequent reaction with $\mathrm{HCl}$.

a)
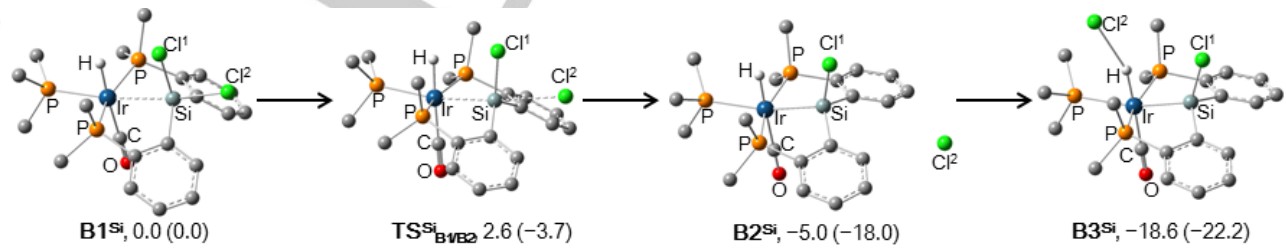

b)
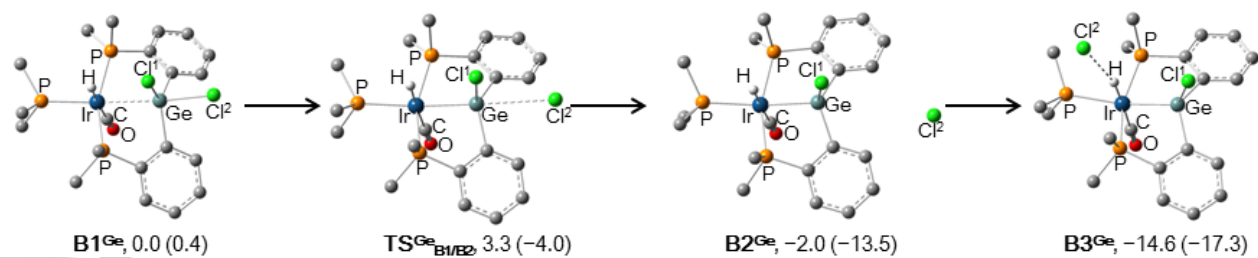

Figure 7. Gibbs energy change in the $\mathrm{Si}-\mathrm{Cl}$ and $\mathrm{Ge}-\mathrm{Cl}$ bond activation with an iridium hydride. The values in parentheses include the solvent effect in toluene $\left(\mathrm{kcal} \mathrm{mol}^{-1}\right)$ 
$=\mathrm{F}, \mathrm{Cl}, \mathrm{C})$. We believe that our analysis of $\mathrm{E}-\mathrm{X} \sigma$-bond cleavage using an iridium hydride not only provides an estimation of $\mathrm{E}-\mathrm{X} \sigma$-bond activation, but also provides an important insight into the strategy to activate strong and polar $\sigma$-bonds involving heavier Group 14 elements with transition metals.

\section{Summary and Outlook}

We reviewed Z-type interaction between a transition metal and saturated heavier Group 14 compound. Significant recent developments in this field were provided using rigid multidentate ligand frameworks that induced relatively stronger interactions. The ortho-phenylene framework developed by Bourissou et al. provided metallosilatrane, -germatrane, and stannatranes of Group 11 metals, which can be regarded as the model compounds for the transition states and intermediates of $\mathrm{S}_{\mathrm{N}}$ 2-type oxidative addition reactions. Our systematic study demonstrated that the strengths of $\mathrm{M} \rightarrow \mathrm{ER}_{3} \mathrm{~F}$ interactions can be attributed to the $\sigma^{*}(\mathrm{E}-\mathrm{F})$ orbital levels strongly related to the geometric environment around $\mathrm{E}$. The $\sigma^{*}(\mathrm{E}-\mathrm{F}) \mathrm{MO}$ levels significantly decreased with the structural change around $E$ atom from tetrahedral to TBP geometry. When going down a group in the periodic table, the isovalent hybridization becomes less effective, and the atomic radius increases, thus facilitating the distortion from a tetrahedral to TBP geometry. Thus, the $\sigma$ electron-acceptor ability of saturated Group 14 ligands increases in the order $\mathrm{Si}<\mathrm{Ge}<\mathrm{Sn}$. In other words, the formation of stronger and more covalent characteristic bonds becomes easier in heavier Group 14 elements because of the rapid formation of antibonding orbitals at a low energy level.

Methimazolyl bridge systems developed by Wagler et al. induce stronger $\mathrm{M} \rightarrow \mathrm{E}$ interactions than ortho-phenylene spacers, because the electronegative nitrogen atoms adjacent to $E$ facilitate the formation of hypervalent structures. For example, paddlewheel-type compounds contain a hexacoordinate $\mathrm{E}$ atom $(\mathrm{E}=\mathrm{Si}, \mathrm{Sn})$ and four methimazoly $(\mathrm{mt})$ bridges, in which $\mathrm{CIE}(\mu \text {-mt })_{4}{ }^{-}$serves as an eight-electron-donor ligand accepting a lone pair of electrons through the Lewis acidic E center. Further, Wagler et al. provided a guiding principle for the assignment of tin compounds wiith an ambiguous oxidation state (e.g., divalent or tetravalent configuration), and described that the penta- and hexacoordinate tin atoms in presumed stannylene complexes potentially involve oxidative addition of more than $+I I$ and serve as $\sigma$-electron acceptor ligands. The pyridine-2-thiolate bridge systems developed by Jambor et al. provided similar findings and further examples of $\mathrm{Pd}-\mathrm{SnR}_{4}$ and $\mathrm{Pt}-\mathrm{SnR}_{4}$ interactions involving stronger covalent characters than even methimazolyl bridge systems.

Kano and Kawashima reported an anionic iron complex with a pentacoordinate germanium ligand, in which the $\mathrm{Fe}-\mathrm{Ge}$ bond length is comparable to the sum of their covalent radii. Moreover, Deng's cobalt complexes with a pentacoordinate silicon ligand showed a very short Co-Si distance. The NLMO analysis of their compounds indicates that the $\mathrm{Fe}-\mathrm{Ge}$ and Co-Si bonds have strong covalent characters, even though the $\mathrm{Fe}-\mathrm{Ge}$ bond still may have stronger contributions of $\mathrm{Fe}^{0} \rightarrow \mathrm{Ge}^{\mathrm{IV}}$ description rather than $\mathrm{Fe}^{\|}-\mathrm{Ge}^{\mathrm{I}}$ description. These findings clearly indicate that even lighter Si and Ge atoms than Sn can form very strong $M-E R_{4}$ bonds with a significant covalent character in a manner similar to $\mathrm{Sn}$.

The facile construction of dative $\mathrm{M} \rightarrow \mathrm{ER}_{4}$ interactions enabled us to investigate the activation reactions of polar and strong bonds such as $\mathrm{Si}-\mathrm{F}, \mathrm{Ge}-\mathrm{F}, \mathrm{Si}-\mathrm{Cl}$, and $\mathrm{Ge}-\mathrm{Cl}$ bonds. The pentacoordinate silicon or germanium compounds bearing a dative $\mathrm{M} \rightarrow \mathrm{ER}_{3} \mathrm{X}$ bond $(\mathrm{E}=\mathrm{Si}, \mathrm{Ge} ; \mathrm{X}=\mathrm{F}, \mathrm{Cl}$ ) were the key intermediates in the bond activation reactions. The E-F and $\mathrm{E}-\mathrm{Cl}$ bonds in the intermediates weakened, leading to subsequent bond activations with an iridium hydride. Our findings pave the way for the catalytic cleavage of E-F and $\mathrm{E}-\mathrm{Cl}$ bonds using transition metals. The bond activation strategy based on the dative $\mathrm{M} \rightarrow \mathrm{ER}_{3} \mathrm{X}$ bond may become a new general method for the transition-metal-mediated activation and transformation of strong and polar $\sigma$-bonds.

\section{Acknowledgements}

Fruitful collaborations with S. Sakaki and D. Bourissou are gratefully acknowledged.

Keywords: hypervalent compounds $\cdot \sigma$-electron acceptor ligands • heavier Group 14 elements • Si-F activation • transition metals

[1] a) H. Nakai, M. Okoshi, T. Atsumi, Y. Kikuchi, K. Akiba, Bull. Chem Soc. Jpn. 2011, 84, 505-510 and references cited therein.

[2] a) D. Kost, I. Kalikhman, in The Chemistry of Organic Silicon Compounds, Vol. 2 (Eds.: Z. Rappoport, Y. Apeloig), John Wiley \& Sons, Inc., 1998, Chapter 23; b) Y. I. Baukov, S. N. Tandura, in The Chemistry of Organic Germanium, Tin and Lead Compounds, Vol. 2 (Ed.: Z. Rappoport), John Wiley \& Sons, Inc., 2002, Chapter 16; c) , K $-\mathrm{y}$. Akiba, in Chemistry of Hypervelent Compounds; John Wiley \& Sons, 1999.

[3] B. Cordero, V. Gómez, A. E. Platero-Prats, M. Revés, J. Echeverría, E. Cremades, F. Barragán, S. Alvarez, Dalton Trans. 2008, 37, 28322838.)

[4] A. R. Bassindale, S. J. Glynn, P. G. Taylor, in The Chemistry of Organic Silicon Compounds, Vol. 2 (Eds.: Z. Rappoport, Y. Apeloig), John Wiley \& Sons, Inc., 1998, Chapter 9.

[5] J. F. Hartwig, Organotransition Metal Chemistry from Bonding to Catalysis; University Science Books: Sausalito, 2010.

[6] a) J. K. Stille, K. S. Y. Lau, Acc. Chem. Res. 1977, 10, 434-442; b) N. Rodriguez, C. Ramírez de Arellano, G. Asensio, M. Medio-Simón Chem. Eur. J. 2007, 13, 4223-4229; c) C. Gourlaouen, G. Ujaque, A. Lledós, M. Medio-Simón, G. Asensio, F. Maseras, J. Org. Chem. 2009, 74, 4049-4054

[7] a) M. L. H. Green, J. Organomet. Chem. 1995, 500, 127-148; b) A Amgoune, D. Bourissou, Chem. Commun. 2011, 47, 859-871; c) J. Bauer, H. Braunschweig, R. D. Dewhurst, Chem. Rev. 2012, 112, 4329-4346.

[8] Lange's Handbook of Chemistry, 15th ed. (Eds.: J.A. Dean), McGrawHill, New York, 1999, pp. 4.50. 
[9] a) I. Kuzu, I. Krummenacher, J. Meyer, F. Armbruster, F. Breher, Dalton Trans. 2008, 5836-5865; b) F. G. Fontaine, J. Boudreau, M. H. Thibault, Eur. J. Inorg. Chem. 2008, 5439-5454; c) G. R. Owen, Chem. Soc. Rev. 2012, 41, 3535-3546; d) G. Bouhadir, A. Amgoune, D. Bourissou, Adv. Organomet.Chem. 2010, 58, 1-107; e) H. Kameo, H. Nakazawa, Chem. Asian J. 2013, 8, 1720-1734; f) A. Amgoune, G. Bouhadir, D. Bourissou, Top. Curr. Chem. 2013, 334, 281-311; g) G. Bouhadir, D. Bourissou, Chem. Soc. Rev. 2016, 45, 1065-1079.

[10] M. Sircoglou, S. Bontemps, M. Mercy, N. Saffon, M. Takahashi, G. Bouhadir, L. Maron, D. Bourissou, Angew. Chem. 2007, 119, $8737-$ 8740; Angew. Chem. Int. Ed. 2007, 46, 8583-8586.

[11] J. S. Anderson, M. -E. Moret, J. C. Peters, J. Am. Chem. Soc. 2013 , 135, 534-537.

[12] a) H. Kameo, Y. Hashimoto, H. Nakazawa, Organometallics 2012, 31, 3155-3162; b) H. Kameo, Y. Hashimoto, H. Nakazawa, Organometallics 2012, 31, 4251-4258; c) H. Kameo, H. Nakazawa, Organometallics 2012, 31, 7476-7484.

[13] R. H. Crabtree, in Organometallic Chemistry of the Transition Metals; $6^{\text {th }}$ ed., John Wiley \& Sons, Inc., New Jersey, 2014. Captor 2.

[14] a) J. Grobe, N. Krummen, R. W. Wehmschulte, B. Krebs, M. Laege, Z. Anorg. Allg. Chem. 1994, 620, 1645-1658; b) J. Grobe, R. Wehmschulte, B. Krebs, M. Läge, Z. Anorg. Allg. Chem. 1995, 621 , 583-596.

[15] S. S. Batsanov, Inorg. Mater. 2001, 37, 871-885

[16] J. Grobe, K. Lütke-Brochtrup, B. Krebs, M. Läge, H. -H. Niemeyer, E. U. Würthwein, Z. Naturforsch., 2007, 62b, 55-65.

[17] P. Gualco, T. -P. Lin, M. Sircoglou, M. Mercy, S. Ladeira, G. Bouhadir, L. M. Pérez, A. Amgoune, L. Maron, F. P. Gabbaï, D. Bourissou, Angew. Chem. 2009, 121, 10076-10079; Angew. Chem. Int. Ed. 2009, 48, 9892-9895.

[18] P. Gualco, M. Mercy, S. Ladeira, Y. Coppel, L. Maron, A. Amgoune, D. Bourissou, Chem. Eur. J. 2010, 16, 10808-10817.

[19] N. Kano, F. Komatsu, M. Yamamura, T. Kawashima, J. Am. Chem. Soc. 2006, 128, 7097-7109.

[20] P. Gualco, S. Ladeira, H. Kameo, H. Nakazawa, M. Mercy, L. Maron, A. Amgoune, D. Bourissou, Organometallics 2015, 34, 1449-1453.

[21] In fact, other examples of the trigonal monopyramidal gold center are limited to complexes bearing a triphosphine-borane ligand. See $\mathrm{S}$. Bontemps, G. Bouhadir, W. Gu, M. Mercy, C. -H. Chen, B. M. Foxman, L. Maron, O. V. Ozerov, D. Bourissou, Angew. Chem. 2008, 120, 1503-1506; Angew. Chem. Int. Ed. 2008, 47, 1481-1484.

[22] H. Kameo, T. Kawamoto, S. Sakaki, D. Bourissou, H. Nakazawa, Organometallics, 2015, 34, 1440-1448.

[23] a) H. Kameo, T. Kawamoto, S. Sakaki, H. Nakazawa, Organometallics 2014, 33, 5960-5963; b) H. Kameo, T. Kawamoto, D. Bourissou, S. Sakaki, H. Nakazawa, Organometallics 2014, 33, 6557-6567.

[24] W. Kutzelnigg, Angew. Chem. Int. Ed. Engl. 1984, 23, 272-295.

[25] J. Wagler, A. F. Hill, T. Heine, Eur. J. Inorg. Chem. 2008, 4225-4229.

[26] J. Wagler, E. Bredler, Angew. Chem. 2010, 122, 634-637; Angew. Chem. Int. Ed. 2010, 49, 624-627.

[27] L. A. Truflandier, E. Brendler, J. Wagler, J. Autschbach, Angew. Chem. 2011, 123, 269-273; Angew. Chem. Int. Ed. 2011, 50, 255-259.

[28] J. Autschbach, K. Sutter, L. A. Truflandier, E. Brendler, J. Wagler, Chem. Eur. J. 2012, 18, 12803-12813.

[29] S. Sakaki, D. Kawai, S. Tsukamoto, Collect. Czech. Chem. Commun. 2011, 76, 619-629.
[30] E. Brendler, E. Wächtler, T. Heine, L. Zhechkov, T. Langer, R. Pöttgen, A. F. Hill, J. Wagler, Angew. Chem. 2011, 123, 4793-4797; Angew. Chem. Int. Ed. 2011, 50, 4696-4700

[31] a) Y. Cabon, H. Kleijn, M. A. Siegler, A. L. Spek, R. J. M. K. Gebbink, B. -J. Deelman, Dalton Trans., 2010, 39, 2423-2427; b) Y. Cabon, I. Reboule, M. Lutz, R. J. M. K. Gebbink, B. -J. Deelman, Organometallics, 2010, 29, 5904-5911; c) E. J. Derrah, S. Warsink, J. J. M. de Pater, Y. Cabon, I. Reboule, M. Lutz, R. J. M. K. Gebbink, B. J. Deelman, Organometallics, 2014, 33, 2914-2918. Further examples have been reported. see d) S. Warsink, E. J. Derrah, C. A. Boon, Y Cabon, J. J. M. de Pater, M. Lutz, R. J. M. K. Gebbink, B. -J. Deelman, Chem. Eur. J., 2015, 21, 1765-1779.

[32] J. Martincová, L. Dostál, S. Herres-Pawlis, A. Růžička, R. Jambor, Chem. Eur. J. 2011, 17, 7423-7427.

[33] E. Wächtler, R. Gericke, L. Zhechkov, T. Heine, T. Langer, B. Gerke, R. Pöttgen, J. Wagler, Chem. Commun. 2014, 50, 5382-5384.

[34] Wahlicht, E. Brendler, T. Heine, L. Zhechkov, J. Wagler, Organometallics 2014, 33, 2479-2488.

[35] N. Kano, N. Yoshinari, Y. Shibata, M. Miyachi, T. Kawashima, M. Enomoto, A. Okazawa, N. Kojima, J. -D. Guo, S. Nagase, Organometallics 2012, 31, 8059-8062.

[36] J. Sun, C. Ou, C. Wang, M. Uchiyama, L. Deng, Organometallics, 2015, 34, 1546-1551.

[37] H. Kameo, T. Kawamoto, S. Sakaki, D. Bourissou, H. Nakazawa, Chem. Eur. J. 2016, 22, 2370-2375

[38] Examples of transition-metal-mediated cleavages of Si-F $\sigma$-bond have been limited to relatively reactive $\mathrm{Si}-\mathrm{F}$ bonds in hypervalent silicon species. a) R. R. Burch, R. L. Harlow, S. D. Ittel, Organometallics 1987, 6, 982-987; b) S. K. Agbossou, C. Roger, A. Igau, J. A. Gladysz Inorg. Chem. 1992, 31, 419-424; c) C. M. Jones, N. M. Doherty, Polyhedron, 1995, 14, 81-91; d) J. E. Veltheer, P. Burger, R. G Bergman, J. Am. Chem. Soc. 1995, 117, 12478-12488; e) A. L. Raza, T. Braun, Chem. Sci. 2015, 6, 4255-4260.

[39] Prediction of difficulty in oxidative addition of Si-F $\sigma$-bond. (a) $\mathrm{S}$ Sakaki M. leki, J. Am. Chem. Soc. 1993, 115, 2373-2381; b) $\mathrm{H}$. Kameo, S. Sakaki, S. Chem. Eur. J. 2015, 21, 13588-13597.

[40] H. Kameo, K. Ikeda, D. Bourissou, S. Sakaki, S. Takemoto, H. Nakazawa, H. Matsuzaka, Organometallics 2016, 35, 713-719.

[41] H. Kameo, K. Ikeda, S. Sakaki, H. Nakazawa, S. Takemoto, H. Matsuzaka. Dalton Trans. 2016, 45, 7570-7580

[42] a) A. A. Zlota, F. Frolow, D. Milstein, J. Chem. Soc., Chem. Commun. 1989, 1826-1827; b) B. J. Rappoli, T. S. Janik, M. R. Churchill, J. S. Thompson, J. D. Atwood, Organometallics 1988, 7, 1939-1944; c) H. Yamashita, M. Tanaka, M. Goto, Organometallics 1997, 16, 46964704; d) F. Stöhr, D. Sturmayr, G. Kickelbick, U. Schubert, Eur. J Inorg. Chem. 2002, 2305-2311; e) H. Yoo, P. J. Carroll, D. H. Berry, J. Am. Chem. Soc. 2006, 128, 6038-6039; f) S. Gatard, C. -H. Chen, B. M. Foxman, O. V. Ozerov, Organometallics 2008, 27, 6257-6263; g) S J. Mitton, R. McDonald, L. Turculet, Organometallics 2009, 28, 5122 5136; h) P. J. Tiong, A. Nova, E. Clot, P. Mountford, Chem. Commun. 2011, 47, 3147-3149; i) Y. Kim, H. Y. Woo, S. Hwang, Bull. Korean Chem. Soc. 2011, 32, 2479-2481; j) T. Asaeda, J. Y. Lee, K. Watanabe, M. Minato, Chem. Lett. 2014, 43, 1005-1007.

[43] a) J. Kuyper, Inorg. Chem. 1978, 17, 77-81; b) C. J. Levy, J. J. Vittal. R. J. Puddephatt, Organometallics 1996, 15, 2108-2117; c) C. J. Levy, R. J. Puddephatt, J. Am. Chem. Soc. 1997, 119, 10127-10136. 
Entry for the Table of Contents (Please choose one layout)

Layout 2:

\section{PERSONAL ACCOUNT}

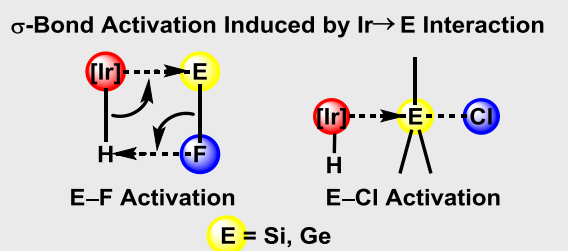

Recent significant studies on bonding between transition metals ad saturated heavier Group 14 compounds (dative $\mathrm{M} \rightarrow \mathrm{E}$ bonds) enable a deep understanding of this novel bonding situation. In this review, we mainly focused on the chemistry of $\sigma$-acceptor (Z-type) saturated heavier Group 14 ligands, particularly the bonding characters. The bond activation reactions initiated by dative $\mathrm{M} \rightarrow \mathrm{E}$ interactions are also summarized.
Hajime Kameo, * Hiroshi Nakazawa*

Page No. - Page No.

Saturated Heavier Group 14

Compounds as $\sigma$-Electron Acceptor

(Z-type) Ligands 